\title{
Leveraging Big Data Analytics to Improve Quality of Care in Healthcare Organisations: A Configurational Perspective
}

\author{
Yichuan Wanga; LeeAnn Kung ${ }^{\mathrm{b}}$; Suraksha Gupta ${ }^{\mathrm{a}}$; Sena Ozdemir ${ }^{\mathrm{c}}$
}

${ }^{a}$ Newcastle University Business School, Newcastle University, 102 Middlesex St, London E1 7EZ, United Kingdom

${ }^{\mathrm{b}}$ Department of Information Systems, College of Business, Georgia Southern University, United States

${ }^{c}$ Coventry University, Business School, Jaguar Building, Priory Street, Coventry CV1 5FB, United Kingdom

E-mail: yi-chuan.wang@ @ewcastle.ac.uk (Y.Wang), lkung@georgiasouthern.edu

(L. Kung); suraksha.gupta@ newcastle.ac.uk (S. Gupta), ac7687@ coventry.ac.uk (S. Ozdemir) 


\begin{abstract}
Big data analytics (BDA) is beneficial for organisations, yet implementing BDA to leverage profitability is fundamental challenge confronting practitioners. Although prior research has explored the impact that BDA has on business growth, there is a lack of research that explains the full complexity of BDA implementations. Examination of how and under what conditions BDA achieve organisational performance from a holistic perspective is absent from the existing literature. Extending the theoretical perspective from the traditional views (e.g. resource-based theory) to configuration theory, we have developed a conceptual model of BDA success that aims to investigate how BDA capabilities interact with complementary organisational resources and organisational capabilities in multiple configuration solutions leading to higher quality of care in healthcare organisations. To test this model, we use fuzzy-set qualitative comparative analysis (fsQCA) to analyse multi-source data acquired from a survey and databases maintained by the Centres for Medicare \& Medicaid Services. Our findings suggest that BDA when given alone, is not sufficient in achieving the outcome but is a synergy effect in which BDA capabilities and analytical personnel's skills together with organisational resources and capabilities as supportive role can improve readmission rates and patient satisfaction in healthcare organisations.
\end{abstract}

Keywords: Big data analytics, Fuzzy-set qualitative comparative analysis (fsQCA), quality of care, configuration theory, resource-based theory 


\section{Introduction}

Constantly increasing large volumes of data in various formats (from electronic health records; EHRs) and other data sources such as pharmaceutical events, insurance claims/billing, and R\&D laboratories) is challenging healthcare organisations' data management capabilities. The need for better data management is not unique to healthcare but it is more vital in healthcare because it concerns patients' well-being, which is more important than the bottom line in other industries. Indeed, excellent data management could facilitate reliable predictions of patient behaviour, medical knowledge creation and clinical practice improvements (Kallinikos and Tempini, 2014; Raghupathi and Raghupathi, 2014). However, many healthcare organisations are suffering from a lack of data standards and integration, data overload issues and barriers to the collection of highquality data that result in billing errors, medical mistakes, and generating unnecessary costs (Ward, Marsolo, and Froehle, 2014). Data quality depends not only on its own features but also on the business environment using the data, including business processes and business users. Only the data that conform to the relevant uses and meet requirements can be considered qualified (or good quality) data. Big data analytics (BDA) is increasingly being endorsed for its potentially crucial role in addressing these challenges in healthcare sectors. Yet our knowledge regarding how BDA can be implemented into practice and how it impacts on organisational performance still remains limited.

Prior research has explored the impact that BDA has on business growth through the lens of resource-based theory (RBT), knowledge-based view (KBV), and information processing view (IPV). Several scholars have drawn upon RBT to conceptualise a BDA capability by orchestrating tangible and intangible big data and human resources to business process and to examine its direct effects on operational and strategic-level performance (Akter, Wamba, Gunasekaran, Dubey and Childe, 2016; Gupta and George, 2016; Trkman et al., 2010; Wamba, Gunasekaran, Akter, Ren, 
Dubey and Childe, 2017; Wang and Hajli, 2017). Proponents of KBV consider BDA application an effective tool to acquire and harness knowledge which enables firms to create organisational agility and competitive advantage (Côrte-Real, Oliveira and Ruivo, 2017; Wang and Byrd, 2017; $\mathrm{Xu}$, Frankwick and Ramirez, 2016). Some scholars use IPV to explain how BDA can help firms manage task complexity and respond to environmental changes through the mechanisms of information processing (Cao, Duan and Li., 2015; Srinivasan and Swink, in press). However, no prior research is capable of explaining the full complexity of BDA implementations nor examine how and under what conditions BDA can achieve organisational performance from a holistic perspective in the healthcare context. This leads to our research question: What configurations of BDA capabilities, complementary organisational resources, and organisational capabilities lead to improved healthcare performance?

In the attempt to answer this question, we first propose a conceptual model with a set of BDA success elements. A set of BDA capability that consists of BDA technological and human resources from the existing literature is identified. We then go on to explore other organisational elements (i.e. complementary organisational resources and organisational capabilities) to be considered as the potential impact of BDA on healthcare performance.

Second, we draw on the configuration theory approach (El Sawy, Malhotra, Park and Pavlou, 2010) to explain how BDA and other organisational elements simultaneously combine to achieve healthcare performance (i.e. low average excess readmission and high total performance score). Configuration theory emerged from organisational research and strategic management (Fiss, 2007; Fiss, Cambré and Marx, 2003). The core concept of this theory, configuration, is defined as "a specific combination of causal elements or conditions that generate an outcome of interest" (El Sawy et al., 2010, p. 838). This approach allows us to understand how organisations can create 
business value from BDA by exploring the complex patterns and combinations of interconnected elements. Given that BDA's business value generation is a complex process resulting from multiway interactions among multiple elements, we argue that configuration theory provides an excellent anchor to explain the creation of BDA's business value and explore the configurational effects of BDA capability and organisational elements on improving quality of care in healthcare. We accordingly utilise a set-theoretic configurational method - fuzzy-set qualitative comparative analysis (fsQCA) - as our data analysis approach.

Our study makes contributions to the management literature in three ways. First, this research proposes a conceptual model with a configurational lens to explicate the complexity of big data analytics implementation. To the best of our knowledge, as yet, no previous studies have considered the complex interactions among BDA and the organisational elements driving organisational performance in the healthcare context. Second, the configurations we identified provide evidence regarding the ways the different relational aspects interact with each other to create high performance in healthcare. This thus extends and deepens our understanding of how big data analytics can be implemented into practice. It could be a useful guidance for practitioners, outlining a variety of paths that they can follow depending on their specific circumstances. Finally, from a methodological standpoint, this study contributes by exemplifying complementarities of fsQCA and regression-based methods. The regression-based method is suitable for explaining the causal paths through which BDA impacts organisational performance, whereas fsQCA provides a deeper understanding of the complex, non-linear and synergistic effects of BDA and organisational elements on organisational performance.

\section{Theoretical Background and Research Model}




\subsection{Brief Review: Path to Big Data Analytics Success}

Big data was first defined in terms of its volume, velocity, and variety (3Vs), then a fourth $\mathrm{V}$ was added, veracity which refers to data accuracy that relates to quality. After which it became possible to develop more sophisticated data analysis software to fulfil the needs of handling the information explosion according to the way it is accessed, searched, processed and managed (Gandomi and Haider, 2015). While volume for big data does not have a threshold for measurement as its form can vary depending on the time and style of its collection, it refers to the size, dimension or magnitude measured in terabytes or petabytes (Demchenko, Grosso, Laat and Membrey, 2013). Big data is also explained in terms of variety that explains the structural heterogeneity in a dataset as structured when found in forms of spreadsheets or relational databases; or unstructured data in the form of videos, audios, images, text or tables (Gandomi and Haider, 2015). Velocity in reference to big data reflects the speed, rate or cost at which data is generated using smartphones or other technological advancements like biometric technologies to be analysed (Demchenko et al., 2013). Scholars like Demcheko et al. (2013) have expanded the traditional 3Vs-based definition of big data to its value generation capacity from the analysis based on volume and variety of data available to the analyst.

Veracity is directly related to data quality, as it refers to the inherent biases, noise and abnormality in data. Veracity also includes data consistency (defined by the statistical reliability of data) and data trustworthiness (based on data origin, data collection and processing methods, security infrastructure, etc.). These data quality issues in turn impact data integrity and data accountability. This characteristic of big data presents its importance and challenges especially in Healthcare in needing high level of data analytical capability because it affects the decisions concerning patients' well beings. 
The literature has proposed several conceptual frameworks to explain how to implement BDA in organisations grounded on RBT, KBV, and IPV, as summarized in Table 1 and visualised in Figure 1. Based on RBT, much of the research into big data have found that the different types of BDA resources (e.g., physical, technical and human resources) can add value to firms' operations. These resources can develop BDA-specific capabilities that firms could use to gain meaningful insights and reshape organisational performance. For example, Seddon, Constantinidis and Dod (2012) argue that the functional fit of BDA tools and readily available high-quality data, and staff with good analytical skills, are predictors that positively influence the benefits gained from ongoing BDA improvement projects. A recent study conducted by Wamba et al. (2017) indicated that BDA infrastructure capability, management capability and personnel capability all have a strong effect on firm performance.

As an extension of $\mathrm{RBT}$, the $\mathrm{KBV}$ views knowledge as a value, rare, inimitable, and nonsubstitutable (VRIN) resource, and argues that knowledge absorption plays a critical role in acquiring new knowledge (Grant, 1996). Côrte-Real et al. (2017) have adopted this theory to develop BDA-enabled knowledge assets, namely exogenous knowledge management, endogenous knowledge management and knowledge sharing with partners. They provide evidence from a survey of 500 European firms to suggest that these BDA-enabled knowledge assets create firms' organisational agility, thereby strengthening their competitive advantage. With an emphasis on knowledge absorption, Wang and Byrd (2017) indicate that the effective use of data analysis and interpretation tools in healthcare units indirectly influence decision-making effectiveness through the mediating role of knowledge absorptive capacity.

IPV argues that organisations' performance depends on their ability to process information (Galbraith, 1974). According to this view, Srinivasan and Swink (in press) suggest that the 
application of BDA lies at the heart of organisational information process since it enhances firms' ability to collect, disseminate, store, analyse and display information, all of which strengthens firms' capability to process information. To facilitate organisational information processing capability, prior research has emphasized that organisations should design their organisational structure, mechanism and business processes in conjunction with data analysis processes which may reduce the environmental uncertainty and ambiguity of the problem context (Kowalczyk and Buxmann, 2014; Sharma, Mithas and Kankanhalli, 2014). As regards supply chains, for example, Trkman et al. (2010) report that firms which have the ability to analyse and utilize their information within the different stages of the supply chain (i.e. plan, source, make and deliver) enjoy a superior supply chain performance as a result. In the same vein, Cao et al. (2015) have found that utilizing BDA influences information processing capability through the mediation of a data-driven environment, which in turn, has a positive effect on decision-making effectiveness. These studies explore ways how business decisions are made through the joint effects of BDA and information processing mechanisms. 


\section{Factors leading to BDA success}

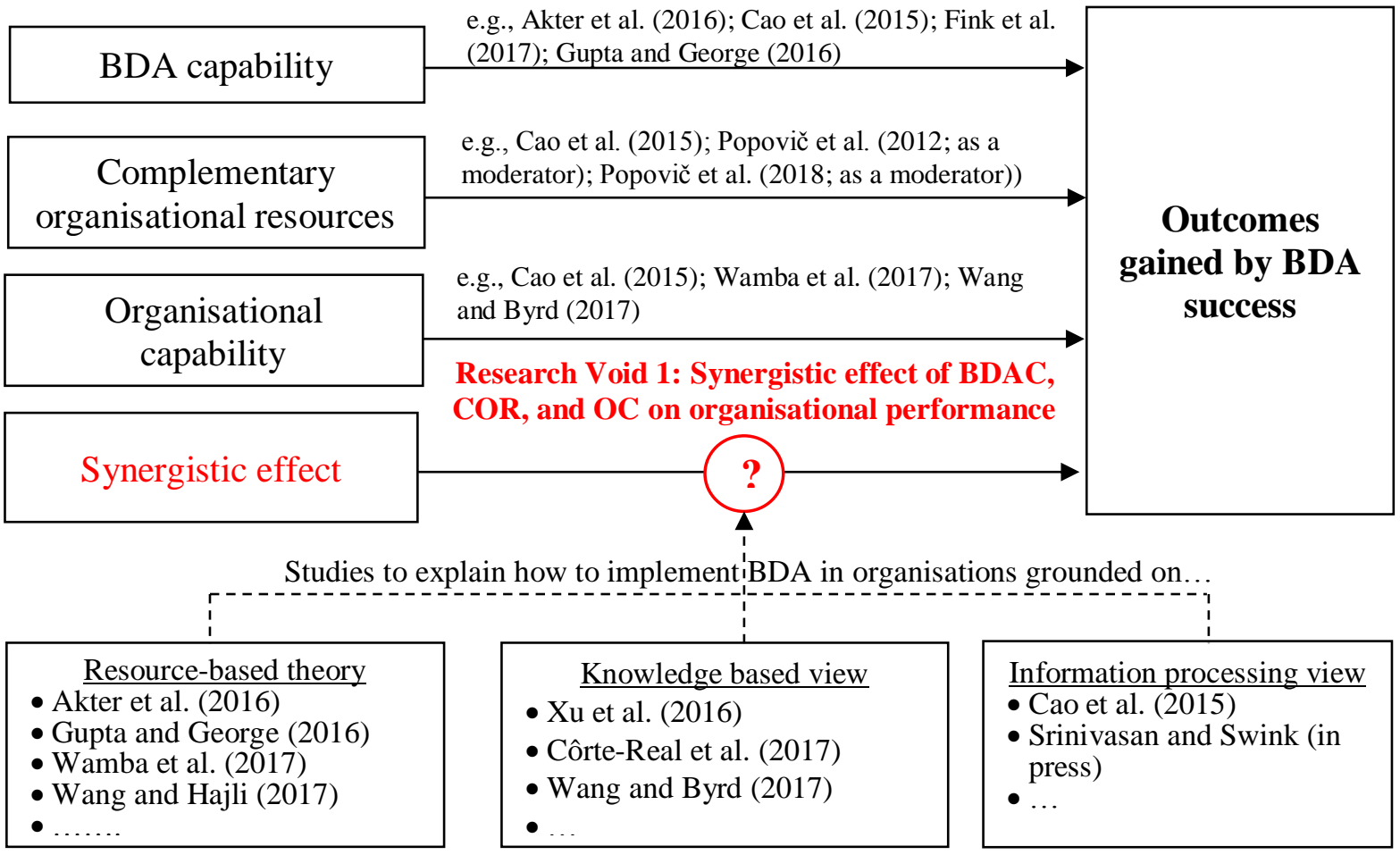

Research Void 2: Configurational perspective in BDA success, especially in the context of health care

Figure 1. Literature on Determinants of Big Data Analytics Success

Table 1. Summary of the literature on BDA models

\begin{tabular}{|c|c|c|c|c|c|c|c|}
\hline \multirow[b]{2}{*}{ Study } & \multirow{2}{*}{$\begin{array}{c}\text { Theoretical } \\
\text { base }\end{array}$} & \multirow[b]{2}{*}{ Methodology-Description } & \multicolumn{3}{|c|}{ Factors leading to BDA success } & \multirow{2}{*}{$\begin{array}{c}\text { Outcomes } \\
\text { gained by } \\
\text { BDA success }\end{array}$} & \multirow[b]{2}{*}{ Causality } \\
\hline & & & BDAC & COR & $\mathrm{OC}$ & & \\
\hline $\begin{array}{l}\text { Akter et al. } \\
(2016)\end{array}$ & RBT & $\begin{array}{l}\text { Empirical- A survey of } 152 \\
\text { BDA professionals toward } \\
\text { understanding the impact of } \\
\text { BDA capabilities on firm } \\
\text { performance }\end{array}$ & $\mathrm{V}$ & & & $\begin{array}{c}\text { Firm } \\
\text { performance }\end{array}$ & $\begin{array}{c}\text { linear } \\
\text { relationship }\end{array}$ \\
\hline $\begin{array}{l}\text { Cao et al. } \\
(2015)\end{array}$ & IPV & $\begin{array}{l}\text { Empirical- A survey of } 740 \\
\text { responses } \\
\text { collected from UK businesses } \\
\text { toward understanding the } \\
\text { impact of business analytics } \\
\text { usage on organisational } \\
\text { decision-making } \\
\text { effectiveness }\end{array}$ & $\mathrm{V}$ & V & $\mathrm{V}$ & $\begin{array}{c}\text { Decision } \\
\text { making } \\
\text { effectiveness }\end{array}$ & $\begin{array}{c}\text { linear } \\
\text { relationship }\end{array}$ \\
\hline
\end{tabular}




\begin{tabular}{|c|c|c|c|c|c|c|c|}
\hline $\begin{array}{l}\text { Fink et al. } \\
\text { (2017) }\end{array}$ & $\begin{array}{l}\text { Contingency } \\
\text { theory }\end{array}$ & $\begin{array}{l}\text { Mixed methods- Develop and } \\
\text { test a model of business } \\
\text { intelligent (BI) value creation } \\
\text { that links BI team, BI } \\
\text { infrastructure, operational } \\
\text { and strategic capabilities to } \\
\text { business value }\end{array}$ & $\mathrm{V}$ & & & $\begin{array}{c}\text { Operational } \\
\text { and strategic } \\
\text { business } \\
\text { value }\end{array}$ & $\begin{array}{l}\text { linear } \\
\text { relationship }\end{array}$ \\
\hline $\begin{array}{l}\text { Gupta and } \\
\text { George } \\
(2016)\end{array}$ & RBT & $\begin{array}{l}\text { Empirical- Create an } \\
\text { instrument to measure BDA } \\
\text { capabilities }\end{array}$ & $\mathrm{V}$ & & & $\begin{array}{c}\text { Market and } \\
\text { operational } \\
\text { performance }\end{array}$ & $\begin{array}{l}\text { linear } \\
\text { relationship }\end{array}$ \\
\hline $\begin{array}{l}\text { Popovič et } \\
\text { al. (2012) }\end{array}$ & $\begin{array}{l}\text { Information } \\
\text { systems } \\
\text { success model }\end{array}$ & $\begin{array}{l}\text { Empirical- A survey-based } \\
\text { study of the impact of } \\
\text { business intelligence systems } \\
\text { maturity on the quality of } \\
\text { information content }\end{array}$ & $\mathrm{V}$ & $\begin{array}{c}\mathrm{V} \\
(\text { as a } \\
\text { moderator) }\end{array}$ & & $\begin{array}{c}\text { The use of } \\
\text { information } \\
\text { in business } \\
\text { process }\end{array}$ & $\begin{array}{l}\text { linear } \\
\text { relationship }\end{array}$ \\
\hline $\begin{array}{l}\text { Srinivasan } \\
\text { and Swink } \\
\text { (in press) }\end{array}$ & IPV & $\begin{array}{l}\text { Empirical- A survey of } 191 \\
\text { global firms toward } \\
\text { examining the impact of } \\
\text { supply chain analytics } \\
\text { capability on operational } \\
\text { performance }\end{array}$ & $\mathrm{V}$ & & $\begin{array}{c}\mathrm{V} \\
(\text { as a } \\
\text { moderator) }\end{array}$ & $\begin{array}{l}\text { Cost } \\
\text { performance } \\
\text { and delivery } \\
\text { performance }\end{array}$ & $\begin{array}{l}\text { linear } \\
\text { relationship }\end{array}$ \\
\hline $\begin{array}{l}\text { Trkman et } \\
\text { al. }(2010)\end{array}$ & $\begin{array}{l}\text { Supply chain } \\
\text { operations } \\
\text { reference } \\
\text { model }\end{array}$ & $\begin{array}{l}\text { Empirical- A survey of } 310 \\
\text { responses from various } \\
\text { industries toward } \\
\text { investigating how the use of } \\
\text { analytics on supply chain } \\
\text { (SC) process influences SC } \\
\text { performance }\end{array}$ & $\mathrm{V}$ & & & $\begin{array}{l}\text { Supply chain } \\
\text { performance }\end{array}$ & $\begin{array}{l}\text { linear } \\
\text { relationship }\end{array}$ \\
\hline $\begin{array}{l}\text { Wamba et } \\
\text { al. (2017) }\end{array}$ & $\begin{array}{l}\text { RBT and } \\
\text { dynamic } \\
\text { capability } \\
\text { view }\end{array}$ & $\begin{array}{l}\text { Empirical- A survey of } 297 \\
\text { Chinese IT managers toward } \\
\text { examining factors that } \\
\text { contribute to improved firm } \\
\text { performance }\end{array}$ & $\mathrm{V}$ & & V & $\begin{array}{c}\text { Firm } \\
\text { performance }\end{array}$ & $\begin{array}{l}\text { linear } \\
\text { relationship }\end{array}$ \\
\hline $\begin{array}{l}\text { Wang and } \\
\text { Hajli (2017) }\end{array}$ & RBT & $\begin{array}{l}\text { Case study- Develop a BDA- } \\
\text { enabled business value model } \\
\text { to explore the cause-and- } \\
\text { effect relationship between } \\
\text { BDA capabilities and } \\
\text { business value }\end{array}$ & $\mathrm{V}$ & & & $\begin{array}{l}\text { Potential } \\
\text { benefits of } \\
\text { BDA }\end{array}$ & $\begin{array}{l}\text { linear } \\
\text { relationship }\end{array}$ \\
\hline $\begin{array}{l}\text { Wang, } \\
\text { Kung, and } \\
\text { Byrd } \\
(2018 \mathrm{a})\end{array}$ & RBT & $\begin{array}{l}\text { Case study- Identify various } \\
\text { BDA functionalities that in } \\
\text { combination build BDA } \\
\text { capabilities from } 26 \\
\text { published case studies }\end{array}$ & $\mathrm{V}$ & & & $\begin{array}{l}\text { Potential } \\
\text { benefits of } \\
\text { BDA }\end{array}$ & - \\
\hline $\begin{array}{l}\text { Wixom et } \\
\text { al. (2013) }\end{array}$ & - & $\begin{array}{l}\text { Case study- explore two key } \\
\text { factors and their underlying } \\
\text { dimensions for maximizing } \\
\text { big data analytics value in a } \\
\text { fashion retailer case }\end{array}$ & $\mathrm{V}$ & & & $\begin{array}{c}\text { Transactional, } \\
\text { informational, } \\
\text { and strategic } \\
\text { vale }\end{array}$ & - \\
\hline $\begin{array}{l}\mathrm{Xu} \text { et al. } \\
(2016)\end{array}$ & KBV & $\begin{array}{l}\text { Conceptual- A theoretical } \\
\text { framework that links } \\
\text { traditional marketing } \\
\text { analytics and BDA to new } \\
\text { product success }\end{array}$ & $\mathrm{V}$ & & & $\begin{array}{l}\text { New product } \\
\text { success }\end{array}$ & $\begin{array}{l}\text { linear } \\
\text { relationship }\end{array}$ \\
\hline
\end{tabular}




\begin{tabular}{|c|c|c|c|c|c|c|c|}
\hline $\begin{array}{l}\text { Côrte-Real } \\
\text { et al. (2017) }\end{array}$ & KBV & $\begin{array}{l}\text { Empirical- a survey of } 500 \\
\text { European firms to suggest } \\
\text { that these BDA enabled } \\
\text { knowledge assets create } \\
\text { firms' organisational agility }\end{array}$ & $\mathrm{V}$ & & & $\begin{array}{l}\text { Organisationa } \\
1 \text { agility }\end{array}$ & $\begin{array}{l}\text { linear } \\
\text { relationship }\end{array}$ \\
\hline $\begin{array}{l}\text { Current } \\
\text { study }\end{array}$ & $\begin{array}{c}\text { Configuration } \\
\text { theory }\end{array}$ & $\begin{array}{l}\text { Empirical- using a multi- } \\
\text { source dataset to examine } \\
\text { how BDA capabilities } \\
\text { interact with complementary } \\
\text { organisational resources and } \\
\text { organisational capabilities in } \\
\text { multiple configurations to } \\
\text { achieve quality of care }\end{array}$ & $\mathrm{V}$ & $\mathrm{V}$ & $\mathrm{V}$ & $\begin{array}{l}\text { Quality of } \\
\text { care }\end{array}$ & $\begin{array}{l}\text { Non-linear } \\
\text { (interaction) } \\
\text { relationship }\end{array}$ \\
\hline
\end{tabular}

Legend: BDAC: big data analytics-enabled capabilities; COR: complementary organisational resources; OC: organisational capabilities

\subsection{Research model of configurations producing organisational performance}

Business value of information technology (IT) literature (e.g. Bharadwaj, 2000; Melville, Kraemer and Gurbaxani, 2004; Nevo and Wade, 2010) contends that IT alone does not unequivocally facilitate organisational performance. Indeed, IT business value creation is a complex process which cannot be fully explained by a set of factors and regression-based methods, but instead involves the systemic and simultaneous arrangement of multiple elements. The link between IT and organisational performance is not likely to be straightforward in terms of the multi-way interactions among the IT elements (e.g. IT infrastructure and IT applications) and other organisational elements (organisational structure and culture). Researchers have emphasized that various complementarities, such as organisational culture, policies and rules, organisational structure and environmental conditions, should interact with IT to generate superior organisational performance (Fichman, 2004; Melville et al., 2004; Nevo and Wade, 2010). For instance, Tanriverdi (2006), who investigates the effects of information technology synergies, ascribes them to a combination of IT resources, namely IT infrastructure, IT strategy, IT human resource, and IT vendor management. In the management research, Zammuto et al. (2007) suggest that it is important to understand the process and outcomes of a combination of IT processes and 
organisations, since either IT or organisational aspects alone would not provide a complete picture of IT business value creation. In information systems strategy research, El Sawy et al. (2010) argue that acquiring strategic advantage in today's turbulent environments is complex, and IT resources alone are not sufficient to explain this complexity. Using fsQCA, El Sawy and his colleagues examined how IT systems, dynamic capability and environmental turbulence interact as digital ecodynamic systems that produce strategic advantages in turbulent environments. These studies extend the theoretical perspective that "business value should be rooted in the identification of IT resources" to encompass "seeking... the best configuration of possible IT resources" (Schryen, 2013). Thus, we adopt configuration theory as a theoretical basis of our research model to explain the complex interactions among BDA capabilities and complementary organisational resources and organisational capabilities and their effects on each other to co-create a higher performance in a healthcare context.

To justify the inclusion of key elements in our research model, we employ the logic structure and rationale of the IT business value generation framework proposed by Melville et al. (2004). This framework demonstrates how business value of IT can be intensified by the bundling of resources (i.e. technology IT resources, human IT resources and complementary organisational resources) and the synthesis and integration of business processes. This framework expands and deepens our understanding of the RBT in an IT context by specifying the underlying mechanisms driving the way IT resources are applied within business processes to improve organisational performance. This framework also explains that the inimitability of rare organisational resources is complementary to technological IT resources and that human IT expertise has a significant potential to improve the operational efficiency of business processes, which in turn spurs economic value for a focal firm. 
Applying this framework to the BDA context, we identified (1) six general categories of BDA capabilities: data integration, analytical, data interpretation, predictive and the technical and business skills of analytics personnel, as components of technological and human IT resources from the extant literature; (2) two complementary organisational resources: evidence-based decision-making culture and data governance and (3) two organisational capabilities embedded in the business process: planned dynamic and improvisational capabilities. These elements can be combined in various potential configurations to determine which options result in improved healthcare performance. Figure 2 illustrates the interactions among these three configuration elements of BDA, with the intersecting orbits representing a holistic confluence that will subsequently contribute to an enhanced quality of care in healthcare. The ten elements included in our configurational analysis are described in the next section.

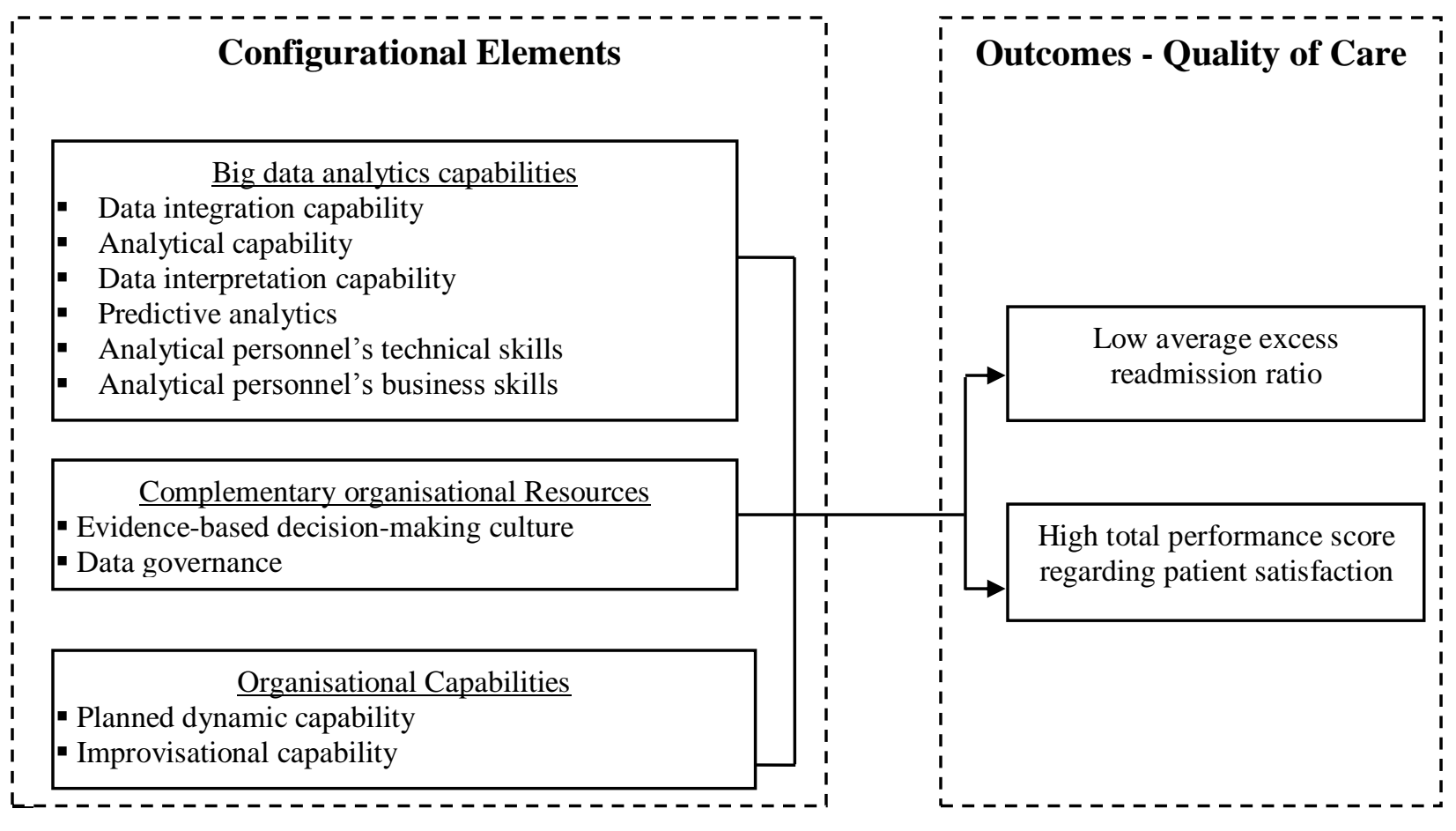

Figure 2. Research Model 


\subsection{The Elements of Big Data Analytics Capabilities}

BDA capability is defined as the ability to acquire, store, process and analyse large amounts of health data in various forms, and deliver meaningful information to users, which allows them to discover business values and insights in a timely fashion (Wang and Hajli, 2017). We propose four dimensions of BDA capability in healthcare: (1) data integration capability, (2) analytical capability, (3) predictive capability, and (4) data interpretation capability, as described below in more detail. The key functionalities and applications in healthcare for each BDA capability are summarized in Table 2.

Table 2. Key functionality and application of BDA capability

\begin{tabular}{|c|c|c|}
\hline BDA capability & Functionalities and tools & Key applications in health care \\
\hline Data integration & $\begin{array}{l}\text { - Middleware } \\
\text { - Data warehouse } \\
\text { - Extract-transform-load } \\
\text { (ELT) tools } \\
\text { - Hadoop distributed file } \\
\text { system (HDFS) } \\
\text { - NoSQL database }\end{array}$ & $\begin{array}{l}\text { - Integrate seamlessly clinical data across } \\
\text { multiple regions or facilities in real-time } \\
\text { or near real-time } \\
\text { - Track medical events based on the rules } \\
\text { that have been built on hospital claims } \\
\text { - Search clinical databases for all data } \\
\text { related to patient characteristics and } \\
\text { conditions }\end{array}$ \\
\hline Analytical & $\begin{array}{l}\text { - Basic statistical analysis } \\
\text { - Online analytical } \\
\quad \text { processing (OLAP) }\end{array}$ & $\begin{array}{l}\text { - Analyse large amounts of clinical data to } \\
\text { understand the past and current state for } \\
\text { specific target variables } \\
\text { - Explore the causes of occurred medical } \\
\text { events from relational databases } \\
\text { - Support real-time processing of multiple } \\
\text { clinical data streams }\end{array}$ \\
\hline Predictive & $\begin{array}{l}\text { - Regression techniques } \\
\text { - Predictive modelling } \\
\text { - Social media analytics } \\
\text { - Machine learning } \\
\text { - Text mining/Natural } \\
\text { Language Processing }\end{array}$ & $\begin{array}{l}\text { - Examine undetected correlations, } \\
\text { patterns, trends between specific } \\
\text { variables of interest across regions or } \\
\text { facilities } \\
\text { - Comparison and cross-referencing of } \\
\text { current and historical data and their } \\
\text { outcomes to predict future trends } \\
\text { - Provide actionable insights or } \\
\text { recommendations in a format readily } \\
\text { understood by its users }\end{array}$ \\
\hline
\end{tabular}




\begin{tabular}{|c|c|c|}
\hline $\begin{array}{l}\text { Data } \\
\text { interpretation }\end{array}$ & $\begin{array}{l}\text { - Visual dashboards/systems } \\
\text { - Reporting } \\
\text { systems/interfaces }\end{array}$ & $\begin{array}{l}\text { - Generate clinical summary (or } \\
\text { performance metrics) in real-time or near } \\
\text { real-time and present in visual } \\
\text { dashboards/systems } \\
\text { - Provide system outputs for role-based } \\
\text { decision-making }\end{array}$ \\
\hline
\end{tabular}

\subsubsection{Data integration capability}

Data integration capability is defined as the ability to transform diverse types of data into a data format that can be read and analysed by the data analysis platform (Wang and Byrd, 2017). Through three key functionalities of data integration in BDA systems (i.e. acquisition, transformation and storage), data can be consistent, visible, easily accessible and interoperable for analysis (Raghupathi and Raghupathi, 2014). A high level of data integration allows healthcare organisations to intelligently aggregate data such as clinical data, billing/insurance data, pharmaceutical R\&D data, and patient behaviour data via extract-transform-load (ELT) tools and provides users with a comprehensive view of these data (Wang, Kung, Wang and Cegielski, 2018b). To make better use of healthcare data, Hsu and Griese (2018) suggest that healthcare organisations should have centralized data deposited in standalone virtual databases linking all data silos for review by medical staff when needed. Data integration driven by BDA systems should also allow users to track the data created by devices worn by individual patients and collect them in real-time or near real-time, making it possible to gather location, event and physiological information, including time stamps, from each patient wearing a device. Hence, since data integration capabilities support healthcare services in value-adding ways, this is viewed as one of the key BDA capabilities in healthcare.

\subsubsection{Analytical capability}


Analytical capability refers to the ability to drive decisions and actions through the extensive use of data and different analytical techniques based on the specific mechanisms used for analytics, thus addressing the various needs of users and other stakeholders (Ghosh and Scott, 2011). In healthcare, the use of analytical tools that can support core clinical operations and processes is particularly important as a means of increasing the quality of care (Raghupathi and Raghupathi, 2014). Healthcare analytical systems allow users to identify patterns of care and discover associations from massive collections of healthcare records, thus providing a broader view for evidence-based clinical practice. Such analysis can identify previously unnoticed patterns in patients related to hospital readmissions and support a better balance between capacity and cost. For example, one effective analytical technique, descriptive analytics, has been widely used in BDA systems (Watson, 2014). In a hospital setting, this technique enables users to understand past patient behaviours and how these behaviours might affect outcomes based on the information stored in their database. Most importantly, the ability to analyse patient preferences helps hospitals to recognize the utility of participating in clinical trials and identify new potential markets. Data analysis can thus help increase the efficiency of healthcare delivery, leading us to include analytical capability as a key dimension of BDA capability.

\subsubsection{Predictive capability}

Predictive capability is "the process of using a set of sophisticated tools to develop models and estimations of what the environment will do in the future" (Wessler, 2013, p. 21). It is the ability to apply diverse statistical analysis methods, modelling, machine learning and data mining to both structured and unstructured data to determine future outcomes. Predictive analysis makes it possible to cross reference current and historical data to generate context-aware recommendations 
that enable managers to make predictions about future events and trends. This capability relies on predictive analytical engines that incorporate a data warehouse, a predictive platform with predictive algorithms (e.g. decision trees, neural networks, and logistic regression) and a predictive interface that provides feedback and recommendations to users.

Predictive capabilities can reduce the degree of uncertainty, enabling managers to make better decisions faster and hence support preventive care. The Texas Health Harris Methodist Hospital Alliance, for example, analyses information from medical sensors to predict patients' movements and thus provide needed services more efficiently. It also monitors patients' actions throughout their hospital stay to help reduce medical risk. For instance, Samorani and LaGanga (2015) combined the predictive analytics with optimization to tackle the problem of overbooking appointments given the predictions of patients' no-show behaviour. Thus, healthcare entities with superior big data predictive capabilities should be able to leverage helpful predictive reports to improve decision-making, optimize existing operations and provide high quality healthcare services.

\subsubsection{Data interpretation capability}

Data interpretation capability emphasizes the ability to produce a healthcare matrix and reports that evaluate patient care and service and identify areas for improvement. In general, data interpretation tools such as dashboards and reporting interfaces yield historical reporting, executive summaries, drill-down queries, statistical analyses and time series comparisons. These outputs can provide a comprehensive view that supports the implementation of evidence-based medicine, detects advanced warnings for disease surveillance, and helps develop personalized patient care (Ghosh and Scott, 2011). 
Data interpretation tools enable data to be visualized in various formats such as interactive dashboards and charts that support physicians and nurses' daily operations and help them to make faster and more rational evidence-based decisions (Roski, Bo-Linn and Andrews, 2014). For example, a Dutch long-term care institution has visualized the number of incidents, the locations where the incidents occurred and the type of physical damage that resulted by mining a collection of 5,692 incidents that occurred over a four-year period (Sprui, Vroon and Batenburg 2014). Displaying frequency tables in the form of visual dashboards has enabled this Dutch long-term care institution to improve patient safety. Therefore, as data interpretation is a critical feature of BDA systems, we propose data interpretation capability as a key element of BDA capability.

\subsubsection{Technical and business skills of analytical personnel}

Davenport, Harris and Morison (2010) define analytical personnel as the members of an organisation who have an analytical mindset and help derive value from BDA. Analytical staff fulfil a hybrid role that requires a broad combination of technical and soft skills and multidisciplinary knowledge domains. The skill sets for analytical personnel have been thoroughly investigated by researchers. The skills needed by well-qualified analytics personnel are summarized in Appendix A. Based on their different levels of data analytical skills, Wilder and Ozgur (2015) categorize analytical staff as data scientists, data specialists and big data analysts.

Data scientists understand how to extract answers to important questions from the tsunami of unstructured information available to them (Davenport and Patil, 2012), while data specialists not only have a solid foundation in computer science, mathematics and management, but also understand how data is managed (Wilder and Ozgur, 2015). Business analysts, who often hold a title such as Chief Data Officer, are key leaders in an organisation and are responsible for 
establishing sound governance to ensure data quality, using data-driven insights to make sound decisions, identify business opportunities and address business problems (Lee et al., 2014). Managers and employees with relevant professional analytical competencies represent a crucial element for BDA success since incorrect interpretations of the reports generated could lead to serious errors of judgment and questionable decisions. Indeed, the success of a BDA project depends on the ability of the organisation's analytical staff to understand not only the overall business environment but also the specific organisational context of the data they work with. Surprisingly little has been reported regarding the role of the analytical personnel as an enabler of BDA success in the existing literature.

The six elements of BDA capabilities discussed above are related but distinct. BDA capability elements by themselves may not explain the actual patterns that reflect the mechanism of the influence of BDA implementation on an outcome of interest. Instead, their interactions and combinations with other organisational elements such as complementary resources and organisational capabilities may determine their role in business value (El Sawy et al., 2010; Melville et al., 2004; Ragin, 2008a). Therefore, we also examined other organisational elements that may influence healthcare performance, along with these BDA capabilities.

\subsection{The elements of complementary organisational resources}

Companies who are eager to implement BDA to create business value must undergo adjustments or even dramatic changes in their day-to-day operations, data policies and organisational culture (Davenport et al., 2010; LaValle et al., 2011). Complementary organisational resources are required for a successful BDA implementation (Watson, 2014). Especially in healthcare, such resources help organisations face the challenges of standardising many different types of data 
across various healthcare systems and resources (Shah \& Pathak, 2014). BDA-enabled complementary organisational resources are regarded as a specific type of organisational resource with the aid of BDA that tend to be tacit, idiosyncratic and deeply embedded in the organisation. Key complementary organisational resources in the context of BDA, such as enterprise-wide analytics orientation (Seddon et al., 2012) and a fact-based decision-making culture (Seddon et al., 2012; Watson, 2014), have been recognized as key drivers of superior organisational performance. In this study, we select an evidence-based decision-making culture and data governance as the primary complementary organisational resources and describe them in the next section.

\subsubsection{Evidence-based decision-making culture}

Organisational culture plays an important role in enabling an organisation to create a business value with analytics (Kiron \& Shockley, 2011). Organisational culture is defined as a set of collective values, beliefs, norms and principles that guide what happens in organisations by defining appropriate behaviour for various situations (Ravasi \& Schultz, 2006). Many studies have reported that organisational culture represents a major hurdle hindering the widespread use of factbased decision-making (e.g. Kiron \& Shockley, 2011; LaValle et al., 2011); shifting the decisionmaking process away from intuitive thinking and individual experience to "the facts" facilitated by BDA is a challenging undertaking for an organisation (Watson, 2014).

This study focuses on a particular aspect of organisational culture from a BDA perspective, namely an evidence-based decision-making culture, defined as a culture of embracing evidencebased management and embedding evidence-based decision-making in the core values and processes of the organisation (Davenport et al., 2010). Kettinger, Zhang, and Marchand (2011) describe this concept as an information-oriented culture where business executives have a 
heightened awareness of information and information management as they make decisions or formulate business strategies. Kiron, Ferguson and Prentice (2013) view this as a data-driven culture, defined as "a pattern of behaviours and practices by a group of people who share a belief that having, understanding and using certain kinds of data and information plays a critical role in the success of their organisation" (p. 18). Researchers suggest that successful analytics use is most likely when an evidence-based decision-making culture is rooted in the enterprise's key business processes, and that this kind of culture would tend to inspire an organisation to measure, test and evaluate quantitative evidence (Davenport, 2006; Kiron, Ferguson and Prentice, 2012). Popovič et al. (2012) found that an organisation with an analytical decision-making culture can positively affect the quality of information provided by business intelligence systems. As noted by Ross, Beath and Quaadgras (2013), building an evidence-based decision-making culture in an organisation should ensure all decision makers share performance metrics that originate from one undisputed source, provide decision makers at all levels with near real-time feedback, articulate business rules and update them with new facts when necessary and provide high quality coaching to decision makers on a regular basis. An evidence-based decision-making culture would allow healthcare organisations to make better use of real-time data, making more accurate diagnoses and better treatment decisions and offering more reliable care to patients.

\subsubsection{Data governance}

Data governance plays a critical role in BDA implementation to ensure the quality, security, privacy and lifecycle of the data that is collected and stored (Khatri \& Brown, 2010). Data governance that is built on IT governance aims to formulate data rules and policies and provide a vision and guidelines relating to privacy, security, lifecycle and ownership of data by aligning the 
objectives of multiple functions (Kooper et al., 2011; LaValle et al., 2011). Typically, a data governance framework is comprised of master data management (MDM), data life cycle management and data security and privacy management. Master data management is regarded as the processes, governance, policies, standards and tools for collecting, aggregating, matching, consolidating, quality-assuring, persisting and distributing data throughout an organisation (Loshin, 2010). The aim of data management is to ensure that data is properly standardised, removed and incorporated to create the immediacy, completeness, accuracy and availability of data needed to support data analysis and decision making. Data lifecycle management is the process of managing business information throughout its lifecycle, from archiving data, via maintaining a data warehouse, testing and delivering different application systems, to deleting and disposing of data (Jagadish et al. 2014). Data security and privacy management is the platform for providing enterprise-level data activities in terms of discovery, configuration assessment, monitoring, auditing and protection. Khatri \& Brown (2010) proposed a hierarchical framework that includes five interrelated decision domains: data principles, data quality, metadata, data access and data lifecycle, for assessing the effectiveness of data governance when implementing BDA in an organisation.

The key to successful data governance is not technology or methods; instead, it is about practices and people in the organisation and their complex ownership of the data that the BDA initiative will affect. Cao et al. (2015) describe this concept in an organisation's data-driven environment as "the organisational practices reflected by developing explicit data strategy and policy to guide analytic activities and designing its structure and process to enable and facilitate BDA activities" (p. 385). Data governance can also be viewed as a set of policies, a way of working, or a framework of optimising the value of information in some sense to the decision makers 
involved (Kooper et al., 2011). As Davenport and Harris (2007) suggest, establishing robust data governance is the first step in implementing BDA. In hospitals, for example, establishing rigorous data policies and data access control mechanisms for highly sensitive healthcare data can prevent security breaches and protect patient privacy (Wang et al., 2018a). Adopting suitable data policies, standards and compliance requirements to restrict users' permissions will ensure the system satisfies healthcare regulations and creates a safe environment for the proper use of patient information. Therefore, we include data governance as an important element in achieving healthcare performance configurations.

\subsection{The elements of organisational capabilities}

To achieve the vast potential of BDA, not only will enterprise IT architectures need to change, but almost every department within a company will also undergo adjustments (Davenport et al., 2010). Managing BDA is not merely a simple technical issue but also a managerial and strategic one (McAfee and Brynjolfsson, 2012). Thus, organisational capabilities have been shown to be significant predictors of BDA success (Wamba et al., 2017; Wang and Byrd, 2017). In general, organisational capability is defined as the ability to adapt to ongoing changes in the business processes and functional activities of the firm (Luo et al., 2012). It has also been described as "an organisation's ability to create value in a unique way by utilizing resources" (Wu \& $\mathrm{Hu}, 2012$, p. 981) from the RBT perspective.

From a dynamic capability perspective, two types of distinctive organisational capabilities planned dynamic capability and improvisational capability - have been identified from among the core business processes for boosting business value (Pavlou and El Sawy, 2010). El Sawy et al. (2010) have highlighted the role of IT systems in shaping these two capabilities and inducing 
environmental turbulence to help build a strategic advantage within digital ecosystems. Planned dynamic capability is a firm's high level organisational ability to integrate, reconfigure, gain and renew resources to match rapidly-changing market environments (Easterby-Smith, Lyles and Peteraf, 2009; Eisenhardt and Martin, 2000; Teece, Pisano and Shuen, 1997) and enhance a firm's agility (Roberts and Grover, 2012). Barreto (2010) and Teece (2007), regard dynamic capability viewing as the ability to sense and shape opportunities and threats, seize market opportunities and maintain competitiveness. In big data research, dynamic capabilities that are triggered by BDA capabilities have been identified as intermediate variables that contribute to firm performance (Côrte-Real et al., 2017; Wamba et al., 2017).

Improvisational capability is defined as an organisation's learned ability to respond to unexpected environmental turbulence quickly, simultaneously forming and executing novel solutions by reconfiguring available resources (El Sawy and Pavlou, 2008). Research from both strategic and organisational management fields has emphasised the importance of organisational improvisation in handling extreme competition, coping with changing circumstances and pursuing potential business opportunities (e.g. Bergh and Lim, 2008; Hadida and Tarvainen, 2014; Moorman and Miner, 1998). Improvisational capability plays a crucial role in building an organisation's agility when reacting to market changes. Such "spontaneous" capabilities enable organisations to make effective and real-time decisions in response to turbulence without having to go through formal planning channels. We thus include planned dynamic capability and improvisational capability as two important organisational capabilities for achieving healthcare performance with BDA. 


\section{Research Methods}

\subsection{Data Collection}

The healthcare industry was selected as the research context for this study for two reasons: (1) BDA implementation and the study of its effects in healthcare industries are lagging far behind other industries such as retail and banking (Raghupathi and Raghupathi, 2014), and (2) focusing on a single industry can mitigate any potential confounding effects due to industry nature and variation. We tested our model using a multi-source dataset acquired from a survey and databases maintained by the Centres for Medicare \& Medicaid Services.

An initial population set of 4668 senior IT executives (primarily Vice Presidents, CIOs, and IT directors) in US hospitals, listing the facility name, job title, phone number and email address for each, was extracted from the Healthcare Information and Management Systems Society (HIMMS) database. After data cleaning to remove incomplete information and duplicates, 3307 senior information system executives remained. An online survey was specifically designed for this study. The first round of 3307 questionnaires resulted in 511 emails being blocked by their organisations' firewall and 1589 emails that were never opened; a gentle reminder was sent a week later. Of the 1207 invitations that were seen by potential respondents, 65 responses were returned, 63 of which were complete and usable for the data analysis, showing a response rate of $5.39 \%$. According to Armstrong and Overton (1977), non-response bias was assessed by comparing the early (first 25\%) and late respondents (last 25\% that are equivalent to non-respondents) for every measurement using paired sample $t$-tests. The results showed no statistically significant difference ( $p>0.05)$ between these two groups, indicating that non-response bias did not present a problem for this study. 
The Centres for Medicare \& Medicaid Services (CMS) data was downloaded from the Hospital Compare website ${ }^{1}$. This website provides information on how well hospitals provide healthcare service to their patients and allows them to compare performance metrics related to certain conditions. We extracted average excess readmission ratios (AERR) and total performance scores (TPS) from the CMS database to evaluate the quality of care as the outcome for this study. We were able to match CMS data to our survey data in 34 cases for AERR and 29 cases for TPS.

\subsection{Measurement Validity and Reliability}

The definitions of key constructs and measurements used in the current study are presented in Appendix B. Most measurement items were adopted from the literature and modified to fit the context of this study. The measurements and items of constructs are presented in Appendix C. Except for the outcome variables, a seven-point Likert-type scale $(1=$ strongly disagree, $7=$ strongly agree) was used for all the constructs.

The validity and reliability of measurements were assessed from the sample data set $(n=63)$ collected for this study. All of the reliability coefficients (Cronbach's alphas) are above 0.70 (Table 4), confirming that the measurements are reliable. Convergent validity was assessed by three criteria: (1) item loading, (2) composite reliability, and (3) average variance extracted (AVE) (Fornell \& Larcker, 1981). As shown in Table 2 and Appendix D, the loadings are all within acceptable ranges, and all but one item for data governance have loadings above the threshold of 0.7. The single item that drops below this level has a loading of 0.650 , which exceeds the acceptable threshold of 0.6 proposed by other scholars (Chin, 1998). The composite reliability scores range from 0.85 to 0.94 . Each AVE is above 0.5 (Table 4), indicating that the latent

\footnotetext{
${ }^{1}$ www.medicare.gov/hospitalcompare
} 
construct can account for at least $50 \%$ of the variance in these items. Two methods were employed to assess discriminant validity: (1) checking whether each item loads more highly on its assigned construct than on other constructs, as suggested by Gefen et al. (2000) and (2) checking whether each construct's square root of AVE is greater than its correlations with other constructs (Table 3) (Fornell \& Larcker, 1981). Each item loading in the cross-loading table (Appendix D) is markedly higher on its assigned construct than on the other constructs. The square root of the AVE is greater than all of the inter-construct correlations (Chin, 1998). Thus, our measurements demonstrate sufficient discriminant and convergent validities.

In addition, to reduce common method bias, we protected respondent-researcher anonymity, provided clear directions and separated the independent and dependent variables (Podsakoff et al., 2003). We then assessed the potential effect of common method bias statistically by conducting two tests. First, Harman's one-factor test (Brewer et al., 1970; Podsakoff \& Organ, 1986) generated ten principal constructs; the unrotated factor solution shows that the first construct explains only $16.74 \%$ of the variance, indicating that our data do not suffer from high common method bias. Second, we compared correlations among the constructs. The results revealed no constructs with correlations over 0.7 , whereas evidence of common method bias ought to have brought about significantly higher correlations ( $<$.90) (Bagozzi et al., 1991). Consequently, these tests suggest that common method bias is not a major concern for this study.

\section{Table 3. Inter-construct correlations}

\begin{tabular}{|l|c|c|c|c|c|c|c|c|c|c|}
\hline Constructs & 1 & 2 & 3 & 4 & 5 & 6 & 7 & 8 & 9 & 10 \\
\hline Data integration capability & $\mathbf{. 8 7}$ & & & & & & & & & \\
\hline Analytical capability & .06 & $\mathbf{. 9 1}$ & & & & & & & & \\
\hline Data interpretation capability & .19 & .25 & $\mathbf{. 9 4}$ & & & & & & & \\
\hline Predictive capability & .09 & .20 & .19 & $\mathbf{. 8 9}$ & & & & & & \\
\hline Technical skills & $.37^{* *}$ & -.21 & -.19 & $.31^{*}$ & $\mathbf{. 8 8}$ & & & & & \\
\hline Business skills & .05 & .02 & .17 & $.25^{*}$ & .23 & $\mathbf{. 8 1}$ & & & & \\
\hline Decision making culture & .14 & .16 & .17 & .03 & -.11 & .16 & $\mathbf{. 8 8}$ & & & \\
\hline
\end{tabular}




\begin{tabular}{|l|c|c|c|c|c|c|c|c|c|c|}
\hline Data governance & -.09 & .21 & $-.27^{*}$ & -.08 & .11 & .10 & $-.26^{*}$ & $\mathbf{. 7 4}$ & & \\
\hline Dynamic capability & $.34 * *$ & -.01 & .10 & .04 & $.32^{* *}$ & -.08 & -.18 & -.06 & $\mathbf{. 8 6}$ & \\
\hline Improvisational capability & -.05 & $-.42^{* *}$ & .19 & .17 & -.15 & .07 & .24 & -.09 & -.10 & $\mathbf{. 8 9}$ \\
\hline
\end{tabular}

Note: $\mathrm{N}=63$; Square root of AVE values are in bold $* \mathrm{p}<0.05 ; * * \mathrm{p}<0.01$

Table 4. Reliability and validity measures of the research model.

\begin{tabular}{|l|c|c|c|c|c|c|c|}
\hline Construct & Items & Mean & SD & Loading & $\begin{array}{c}\text { Composite } \\
\text { Reliability }\end{array}$ & AVE & $\alpha$ \\
\hline Data integration capability & 3 & 4.70 & .99 & $.782-.886$ & .90 & .75 & .85 \\
\hline Analytical capability & 3 & 4.27 & 1.23 & $.802-.913$ & .94 & .83 & .90 \\
\hline Data interpretation capability & 2 & 4.60 & 1.55 & $.843-.907$ & .94 & .89 & .89 \\
\hline Predictive capability & 3 & 4.34 & 1.06 & $.832-.867$ & .92 & .79 & .87 \\
\hline Technical skills & 4 & 5.13 & 1.17 & $.792-.865$ & .94 & .78 & .90 \\
\hline Business skills & 3 & 4.52 & .98 & $.731-.853$ & .85 & .65 & .79 \\
\hline Decision making culture & 3 & 3.80 & 1.27 & $.778-.922$ & .91 & .78 & .86 \\
\hline Data governance & 5 & 3.63 & .92 & $.650-.812$ & .85 & .55 & .84 \\
\hline Dynamic capabilities & 4 & 3.55 & 1.28 & $.715-.915$ & .92 & .74 & .88 \\
\hline Improvisational capabilities & 3 & 3.58 & 1.17 & $.827-.898$ & .92 & .80 & .87 \\
\hline Average excess readmission ratio & - & .999 & .058 & - & - & - & - \\
\hline Total performance score & - & 40.603 & 11.452 & - & - & - & - \\
\hline
\end{tabular}

\subsection{Analysis Method: Fuzzy-set Qualitative Comparative Analysis (fsQCA)}

FsQCA was used to explain how BDA capability, organisational resources and organisational capability elements simultaneously combined to create high quality of care. As our study is to examine the modelling of asymmetric relationships between variables, fsQCA provides several benefits to our study. First, fsQCA focuses squarely on the "middle ground" between variableoriented quantitative methods and case-oriented qualitative methods (Ragin 2000, p.22). It thus allows for evaluating case studies with few cases for standard statistical analyses. Second, regression-based analysis is limited to two-way or three-way interaction effects, while cluster analysis only discovers homogenous patterns without control over the outcome (Fiss, 2007). FsQCA takes the perspective that cases are composed of combinations of theoretically relevant attributes and that the relationships between these attributes and the outcome of interest can be understood through an examination of the subset relations (Ragin, 2000, 2008b). FsQCA could be 
the best approach to deal with multi-way interactions and examine how variables systemically combine to create outcomes (Misangyi et al., 2017).

\subsubsection{Calibration}

A critical step in a fsQCA analysis is to carefully convert data into measures of set membership using theoretical or substantive knowledge external to the empirical data-a process known as calibration. This process transforms interval scale values to fuzzy-set membership scores based on three qualitative anchors: full membership, full non-membership and the crossover point of maximum ambiguity regarding membership in the set of interest (Rai, Patnayakuni, and Seth, 2006). We followed Ragin (2008a) in calibrating fuzzy-set memberships. For each calibration, we set thresholds based on industry common standards, if available, extant theory or substantive knowledge. We used the direct method of calibration in the fsQCA software to transform the measures into set memberships (e.g., Fiss, 2011; Ragin, 2008a). To some extent, survey items that are measured on a Likert scale have built-in membership scores.

As mentioned earlier, we opted to use average excess readmission ratio and TPS as our outcomes. For both measures of quality, we calculated both the national average and the standard deviation. For the first measure of quality of care using the average excess readmission ratio, we set up a "low average excess readmission ratio" set because the lower the ratio the better the quality. A national excess readmission ratio average was calculated by taking the mean of the rate for over 3,500 hospitals located across the United States as the industry standard and the base value to evaluate the membership scores. We also calculated the standard deviation. The cut-off point for full membership for this set was then set as the result of the national average excess readmission ratio minus $1 \mathrm{SD}$ (0.92); the anchor for the cross-over point was 0.99 , the national average excess 
readmission ratio; and the cut-off point for full non-membership was set at the value of the national average excess readmission ratio plus $1 \mathrm{SD}(1.10)$.

For the second measure of quality, we established a "high TPS" set because, as with most performance measures, the higher the score the higher the quality. Two domains, patient experience of care and clinical process of care, were used to assess hospital performance. A performance score and an improvement score were calculated for each measure and a domain score calculated for each of the two domains. The Total Performance Score (TPS) was calculated using the weighted domain scores. The Clinical Process of Care domain score was weighted as $70 \%$ of the TPS, and the Patient Experience of Care domain was weighted as $30 \%$ of the TPS. Using the same statistical measures, the cut-off point for full membership in the high TPS set was 53.14 (national TPS plus 1SD), 40.48 was the score for the cross-over point (national TPS), and 27.82 (national TPS minus 1SD) was the fully-not-in-the-set point.

The configuration conditions selected for this study were: the six BDA capabilities, two complementary organisational resources (i.e. evidence-based decision-making culture and data governance), and two organisational capabilities (i.e. planned dynamic capabilities and improvisational capabilities). All the items for the variables except the BDA capabilities were extracted from the literature and measured using validated scales. As this study used a 7-point Likert scale for the construct survey, we set up the high-level membership sets using 6 as the fully-in-the-set cut-off point, 4 as the cross-over point, and 2 as the fully-not-in-the-set point.

\subsubsection{Truth Table Analysis}

After calibration, sets can be subjected to fuzzy truth table analysis to examine the relationship between the configuration conditions and the outcome. Scholars have recommended testing the 
conditions that might be necessary to achieve the desired outcome before analysing sufficiency (Legewie, 2013), where a "necessary" condition is defined as a condition such that the outcome would not have occurred in its absence. After the necessary conditions analysis, we then ran the truth table algorithm, choosing the outcome and conditions, and applying the standard analysis procedure on fsQCA. Frequency and consistency cut-off points were specified in this step. Here, the minimum acceptable frequency of cases for solutions was set at 1 and the lowest acceptable consistency cut-off at 0.75 , which meets the recommended minimum threshold of 0.75 (Ragin, 2008a). This process clarifies any relationships between combinations of potentially causal or descriptive characteristics and the outcome of interest. The output of a fuzzy-set truth table analysis consists of one or more combinations of characteristics associated with an outcome. We present the results in the next section.

\section{Results of fsQCA analysis}

This section presents the configurations that resulted from the fsQCA analysis of low average excess readmission ratio and high total performance score, shown in Tables 5 and 6 , respectively. The configurations are expressed using the notation system established by Ragin and Fiss (2008). As the data in Tables 5 and 6 reveal, all of the consistency scores for configurations are above the suggested cut-off value of 0.75 (Legewie, 2013), which suggests that the models based on these configurations are adequately specified. FsQCA also yields an overall solution coverage and solution consistency. Overall solution coverage measures the proportion of memberships in the outcome that is explained by the complete solution, while overall solution consistency roughly corresponds to the degree to which these configurations consistently result in high quality. This means that the five solutions listed in Table 4 consistently explain $83.2 \%$ of the low average excess 
readmission ratio, while the four solutions listed in Table 6 consistently explain $75.7 \%$ of high TPS. Overall solution coverage indicates the extent to which these configurations cover high quality of care (Ragin, 2008a). In a fuzzy-set relationship, this states the percentage of the membership of the outcome set that can be captured by the configurations. Here, the complete solution can capture $56.9 \%$ of the low average excess readmission ratio and $55.4 \%$ of high TPS.

Table 5. Configurations for Low Average Excess Readmission Ratio ( $n=34$ cases)

\begin{tabular}{|c|c|c|c|c|c|}
\hline & \multicolumn{5}{|c|}{ Solution } \\
\hline & O1S1 & O1S2 & O1S3 & O1S4 & $01 S 5$ \\
\hline \multicolumn{6}{|l|}{ BDA Capabilities } \\
\hline Data integration capability & $\bullet$ & $\otimes$ & $\bullet$ & $\bullet$ & $\bullet$ \\
\hline Analytical capability & $\mathbf{0}$ & O & O & $\mathbf{0}$ & 0 \\
\hline Data interpretation capability & O & O & O & O & O \\
\hline Predictive capability & $\bullet$ & $\bullet$ & $\bullet$ & $\bullet$ & $\bullet$ \\
\hline Analytics personnel's technical skills & $\bullet$ & $\otimes$ & $\bullet$ & $\bullet$ & $\bullet$ \\
\hline Analytics personnel's business skills & $\bullet$ & $\otimes$ & $\bigotimes$ & $\otimes$ & $\bullet$ \\
\hline \multicolumn{6}{|l|}{ Complementary Organisational Resources } \\
\hline Evidence-based decision-making culture & & $\otimes$ & $\otimes$ & $\otimes$ & $\bullet$ \\
\hline Data governance & $\otimes$ & $\otimes$ & $\otimes$ & $\bullet$ & $\bullet$ \\
\hline \multicolumn{6}{|l|}{ Organisational capabilities } \\
\hline Dynamic capability & $\otimes$ & $\otimes$ & $\bullet$ & $\otimes$ & $\bullet$ \\
\hline Improvisational capability & $\bullet$ & $\otimes$ & $\otimes$ & $\otimes$ & $\bullet$ \\
\hline Consistency & 0.803 & 0.967 & 0.827 & 0.897 & 0.921 \\
\hline Raw Coverage & 0.387 & 0.153 & 0.212 & 0.225 & 0.241 \\
\hline Unique Coverage & 0.159 & 0.036 & 0.022 & 0.032 & 0.053 \\
\hline Overall Solution Consistency & \multicolumn{5}{|c|}{0.832} \\
\hline Overall Solution Coverage & \multicolumn{5}{|c|}{0.569} \\
\hline
\end{tabular}

Note: Black circles $(\mathbf{O})$ indicate the presence of a causal condition, and circles with " $\mathrm{x}$ " $(\otimes)$ indicate absence of a causal condition; big circles = core conditions; small circles = peripheral conditions; Blank spaces indicate "don't care".

Table 6. Configurations for High TPS ( $n=29$ cases)

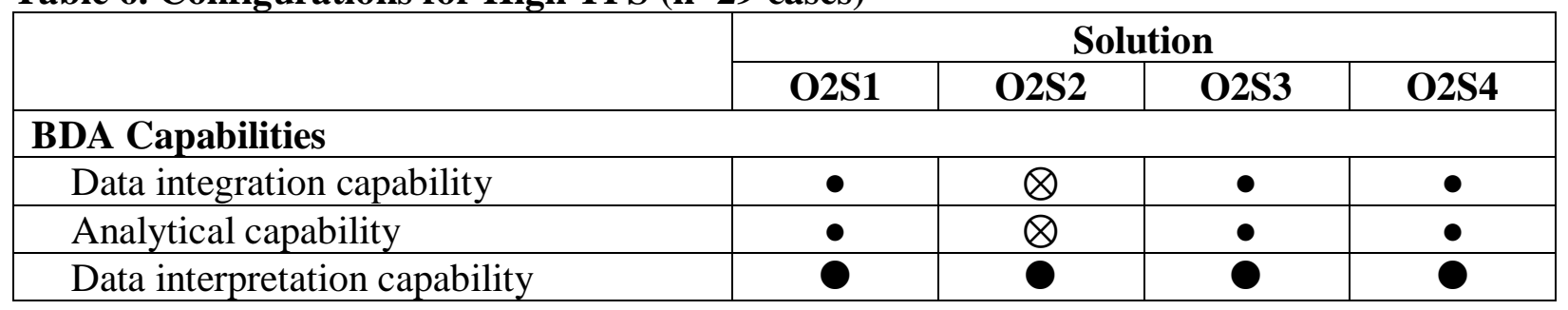




\begin{tabular}{|c|c|c|c|c|}
\hline Predictive capability & $\bullet$ & $\bullet$ & $\bullet$ & O \\
\hline Analytics personnel's technical skills & $\bullet$ & $\otimes$ & $\bullet$ & $\bullet$ \\
\hline Analytics personnel's business skills & O & $\otimes$ & $\otimes$ & $\bullet$ \\
\hline \multicolumn{5}{|l|}{ Complementary Organisational Resources } \\
\hline Evidence-based decision-making culture & & $\otimes$ & $\otimes$ & $\bullet$ \\
\hline Data governance & $\otimes$ & $\otimes$ & $\otimes$ & $\bullet$ \\
\hline \multicolumn{5}{|l|}{ Organisational capabilities } \\
\hline Dynamic capability & $\otimes$ & O & $\bullet$ & $\bullet$ \\
\hline Improvisational capability & $\bullet$ & $\otimes$ & $\otimes$ & $\bullet$ \\
\hline Consistency & 0.779 & 0.922 & 0.724 & 0.919 \\
\hline Raw Coverage & 0.421 & 0.164 & 0.209 & 0.269 \\
\hline Unique Coverage & 0.195 & 0.041 & 0.015 & 0.059 \\
\hline Overall Solution Consistency & \multicolumn{4}{|c|}{0.757} \\
\hline Overall Solution Coverage & \multicolumn{4}{|c|}{0.554} \\
\hline
\end{tabular}

Table 5 shows that, among the five solutions considered, Solution O1S1 has the highest unique coverage score (0.159), indicating that acquiring analytical and data interpretation capabilities from BDA systems with the support of three other BDA capabilities and improvisational capabilities will enable healthcare organisations to reduce their average excess readmission ratio in terms of their clinical processes. The necessary condition analysis for this outcome revealed that analytical capability and data interpretation capability are necessary conditions, with consistency scores of 0.901 and 0.979 , respectively. This implies that for a healthcare organisation to have a low readmission rate, they almost always have high analytical capability and high data interpretation capability. Five different configurations resulted in low average excess readmission ratios, meaning that five different paths could lead to this outcome. All these solutions shared the same two necessary conditions (i.e. data analytics and data interpretation) but these were accompanied by various other combinations of elements. All the four BDA capabilities were either core factors or contributors in all solutions except for data integration capability, which was absent in Solution O1S1. The two complementary organisational resources (evidence-based decision-making culture and data governance) only contributed to 
Solutions O1S4 and O1S5. Solution O1S5 appears especially hard to achieve because it contains all the causal elements; however, it covers $5 \%$ of our cases uniquely, which means that there are healthcare organisations in the United States that are capable of achieving a high level of quality of care by building all their BDA capabilities, including complementary organisational resources, dynamic and improvisational capabilities.

Table 6 shows four potential paths that healthcare organisations could follow to achieve high total performance. The main similarity among these four configurations is the presence of a high level of data interpretation capability from the BDA systems, a necessary condition for this outcome with a score of 0.9 . Solution O2S1 uniquely explains $19.5 \%$ of the variances of high TPS, indicating that a high total performance can be achieved by a high level of data interpretation capability and the cultivation of the analytics personnel's business skills. However, solution O2S2 differs considerably from Solution $\mathrm{O} 2 \mathrm{~S} 1$ in that most elements are absent. Here, only two core elements and one support element are needed for a healthcare organisation to achieve a high TPS, namely high levels of data interpretation capability from BDA systems and dynamic capabilities, with a supportive role for predictive capability from the BDA system. Solution O2S3 shows that a healthcare organisation with high levels of BDA system capabilities, analytics personnel with technical skills and dynamic capabilities for operation can still achieve a high TPS even without high levels of analytics personnel with business skills, an evidence-based decision-making culture, good data governance or improvisational capabilities. Solution O2S4 is identical to Solution O1S5. In this configuration, a healthcare organisation has high levels of all the elements considered in this study. It represents an ideal situation that is far from easy to achieve, as evidenced by its unique coverage of 5.9\%; only two organisations achieved this high level of TPS, largely due to their high levels of BDA system data interpretation capability and predictive capability, supported by the 
BDA system's data integration capability and predictive capability, high levels of both types of analytics personnel's skills (technical and business), and high levels of dynamic and improvisational capabilities.

\section{Discussion}

Our finding reveals that most solutions achieving a high level of quality of care have a high level of analytical and data interpretation capabilities combined with data integration capability, predictive capability and analytics personnel's technical skills. In other words, when a healthcare organisation lacks a high level of organisational capabilities (dynamic and improvisational capabilities) and organisational resources, the combination of BDA capabilities can still give it a low readmission rate. This finding reaffirms the results of studies by Akter et al. (2016) in which the use of BDA can directly improve firm performance. As previously noted, data analytical and interpretation represent the most important components of BDA system for healthcare organisations that encompass the abilities to analyse large amounts of clinical data to understand the past and current state for specific target variables and to generate clinical summary in real-time or near real-time for role-based decision-making. Indeed, our results agree with those reported by Wang et al. (2018b), who indicated that these two BDA capabilities play vital roles in improving the meaningful use of EHR practices and the efficiency of evidence-based medicine practices and meaning, which in turn facilitates quality of care in healthcare.

Surprisingly, the evidence-based decision-making culture is not present in most of the solutions. Unlike the findings reported by previous studies (e.g., Popovič et al., 2012; Ross et al., 2013), our fsQCA result shows that evidence-based decision-making culture is absent in most of the solutions considered, being included only in Solution O1S5 and O2S4. A possible explanation 
for this result is that in a healthcare organisation, such as a clinic, physicians treating patients tend to rely on their professional experience in making decisions, rather than on a system output that they may not be familiar with or been trained to use (Watson, 2014).

It is worth noting that the importance of dynamic and improvisational capabilities is highlighted in some solutions, particularly in developing dynamic capability to improve patient satisfaction $(\mathrm{O} 2 \mathrm{~S} 2, \mathrm{O} 2 \mathrm{~S} 3$, and $\mathrm{O} 2 \mathrm{~S} 4)$. This discovery confirms the findings of several studies (e.g. Côrte-Real et al., 2017; Wamba et al. 2017; Wang \& Byrd, 2017), who report that dynamic capability plays a key role in leading BDA success. Although organisational capabilities have been shown to be significant predictors of business value creation in a number of different contexts (Pavlou \& El Sawy, 2006; 2010), these organisational capabilities are either hard to build or require more long-term planning, so a short-term effect is hard to uncover.

Last but most importantly, one specific capability that is facilitated by BDA systems, data interpretation capability, is the common core causal element of both the desired outcomes considered here. As previously noted, data interpretation capability can generate meaningful clinical summaries in real-time or near real-time and present them in an easily interpreted format using visual dashboards/systems to yield sharable information and knowledge, such as historical reports, executive summaries, drill-down queries, statistical analyses and time series comparisons to different decision makers. As suggested by Wang and Byrd (2017), the ready availability of this information assists healthcare analysts to recognize emerging healthcare issues, such as medical errors, potential patient safety issues or inappropriate medication use, enabling them to alert medical professionals and patients so prompt remedial action can be taken. As incorrect interpretation of the clinical reports generated could lead to serious errors of judgment and questionable decisions, it is important for healthcare organisations to develop interpretation by 
providing analytical training courses to those employees who will play a critical support role in the new information-rich work environment in the earlier stages of BDA adoption.

\subsection{Theoretical implications}

This study is a preliminary attempt to apply configuration logic and the fsQCA approach to understand how healthcare performance can be triggered by BDA. Our findings extend current understanding about big data in terms of $4 \mathrm{Vs}$ (volume, variety, velocity, and veracity) and contribute to the management literature in three ways. First, this study represents a response to an important question raised from Schryen (2013): How do IT resources, IT capabilities and organisational capabilities jointly create business value? Extending beyond traditional interpretations by the RBT, researchers have stressed the particular interrelationships between IT related elements and organisational elements (organisational resources and capabilities) in the IT business value generation process (Kohli and Grover, 2008; Mikalef and Pateli, 2017; Nevo and Wade, 2010). While the existing literature on big data predominantly suggests each BDA element solely leads to organisational performance, this study, which applies fsQCA, provides further evidence to support their view by confirming that BDA implementation does indeed depend on the joint effects of BDA capability, complementary organisational resources and organisational capabilities.

Second, a major debate in the field of management concerning the value of dynamic capability for firm performance has been going on (Easterby-Smith, Lyles, and Peteraf, 2009) since Eisenhardt and Martin (2000) asserted that the value for competitive advantage lies in the resource configurations that they create, not in the capabilities themselves. Kohli and Grover (2008) respond to this debate by arguing firm performance may be the result of particular combinations 
of input elements, such as IT resources and organisational resources. El Sawy et al. (2010) support this view by confirming that a strategic advantage can be built by the holistic confluence among environmental turbulence, dynamic capabilities and IT systems. We clarify this debate by providing further evidence, showing that healthcare performance can be improved in hospitals with dynamic capabilities, in conjunction with the support from the effective use of their analytical and data interpretation capabilities as well as organisational resources such as data governance. This implies that dynamic capabilities cannot by themselves be a source of a sustainable competitive advantage; rather, it should be developed though the synergistic effect of BDA capabilities and other organisational resources.

Finally, organisational capabilities such as dynamic capability and improvisational capability typically play an enabler or a mediator role in linking IT to business value (Pavlou \& El Sawy, 2006; 2010; Wu \& Hu, 2012). Extending the theoretical perspective from a strategic alignment between IT and business to co-evolution, previous studies have suggested that the key to successfully implementing health information technologies (HIT) is to carefully orchestrate the complex and dynamic interactions between organisational capabilities and HIT throughout the business process (Agarwal et al., 2010; Goh, Gao, \& Agarwal, 2011; Novak et al., 2012). Although these studies have mentioned the systemic notion of co-evolution among individual elements for information systems success, examining the effect of co-evolution with conventional correlationbased linear methods (e.g. two-way correlations, testing moderator/mediator effect) does not support the holistic view required to capture the non-linear interdependent interactions among these elements. To the best of our knowledge, this is among the first study that examines the complex interactions among BDA and the organisational capabilities driving healthcare performance. 


\subsection{Managerial implications}

From a practical perspective, our study advances an understanding of the "black box" between BDA and firm performance by exploring the complex causality among BDA capabilities, complementary organisational resources and organisational capabilities. Our findings not only reveal the synergy effect of BDA capabilities and BDA human resources (which here refers to the technical skills of the organisation's analytics personnel) in achieving improved readmission rates and patient satisfaction, but also show that BDA cannot achieve this in isolation from other elements, as organisational resources and capabilities play a supportive role. These fsQCA results provide the "secret recipes" needed to achieve healthcare performance by considering the presence or absence of the various "ingredients". These secret recipes could be the useful solutions for healthcare practitioners, leveraging BDA to improve healthcare performance. By comparing the similarities and differences between multiple equifinal configurations, we extract patterns that produce the desired level of healthcare quality in terms of improved readmission rates and patient satisfaction. Based on the patterns identified, healthcare organisation managers can adopt solutions specifically tailored to their own characteristics or situations to achieve high healthcare quality and avoid the expensive pitfalls of misplaced BDA investments.

In practice, most organisations continue to struggle to make progress on their BDA initiatives because implementing a BDA system can be an expensive and risky undertaking (Watson, 2014). It typically costs a big data project approximately $\$ 9.3$ million to build and maintain a Hadoop system over a 5-year period (Winter, Gilbert, and Davis, 2013). Our fsQCA results offer a set of useful configurational solutions to achieve high quality of care so that it enables healthcare organisations to develop a clear path to BDA success. 


\section{Limitations and Future Research}

While we believe that the fsQCA method can contribute to our research, this method suffers from a number of limitations. First and foremost, fsQCA depends on prior knowledge or an extensive literature on the subject to select appropriate conditions and outcomes and reduce the number of configurations to a manageable level (Liu et al., 2017). The configurations are sensitive to the range of conditions included - adding or removing conditions could result in very different solutions. Although the selection of the conditions in our analysis was built on the business value of IT generation framework provided by Melville et al. (2004) and was informed by a comprehensive review of the extant literature on BDA, the conditions we chose came mainly from exploratory studies or case studies, with little support from empirical evidence. As a result, one or more care quality drivers could have been overlooked or overestimated. To address this concern, a more rigorous study should be conducted to identify what constitutes stable conditions, for example, by incorporating a mixed method research design, such as a qualitative Delphi approach, and content analysis to provide a stronger basis for condition selection.

Secondly, there are limitations and disadvantages related to our dataset. A major limitation is the small sample size for our matchup dataset. Although fsQCA is sensitive to case selection (Liu et al., 2017), it does allow for the analysis of small to medium numbers of cases (e.g. 10 to 50) that traditional regression-based methods may not be able to solve (Ragin, 2008b). We also sought to address real-world issues by using actual measures, such as the average excess readmission ratio from the CMS database, for assessing healthcare performance rather than scaled self-reporting performance. Adopting this approach enabled us to more accurately interpret the implications of each configuration. As fsQCA requires larger samples (50+ cases) to reduce 
contradictions, healthcare researchers may want to consider a second analysis using fsQCA data from Healthcare Information and Management Systems Society (HIMSS) and CMS databases, which contain a large number of cases that could be utilized to develop robust IT business value explanatory models.

\section{Conclusion}

In summary, rather than simply exploring the direct effect of BDA on healthcare performance through a traditional linear causal analysis - as tends to be the case in existing big data research we have focused on examining the systemic, equifinal and discontinuous interactions among BDA elements and other organisational elements. Applying configuration theory and fsQCA in this study has allowed us to discover not only single drivers, but also sets of conditions that determine the quality of care triggered by BDA in healthcare. These findings from fsQCA advance our understanding of how BDA-enabled IT capabilities combine with other organisational elements to achieve business value in healthcare. Most importantly, we offer evidence that different solutions leading to the same healthcare performance due to the effective use of IT and other organisational elements do indeed exist. This demonstrates that fsQCA is a useful and appropriate tool for assessing the business value of BDA that can offer new insights to improve our understanding of the factors contributing the business value of BDA. As the use of fsQCA is still in its infancy in most business domains, more substantive discussions of the possibilities opened up by this new approach are needed if we are to reap the full benefit of applying fsQCA to investigations of the impact of new technology on firm performance. 


\section{References}

Agarwal, R., G. Gao, C. DesRoches and A. K. Jha (2010). 'Research commentary - The digital transformation of healthcare: Current status and the road ahead', Information Systems Research, 21, pp. 796-809.

Akter, S., S. F. Wamba, A. Gunasekaran, R. Dubey and S. J. Childe (2016). 'How to improve firm performance using big data analytics capability and business strategy alignment?', International Journal of Production Economics, 182, pp. 113-131.

Armstrong, J. S. and T. S. Overton (1977). 'Estimating nonresponse bias in mail surveys', Journal of Marketing Research, 14(3), pp. 396-402.

Bagozzi, R. P., Y. Yi and L. W. Phillips (1991). 'Assessing construct validity in organisational research', Administrative Science Quarterly, 36(3), pp. 421-458.

Bardhan, I. R. and M. F. Thouin (2013). 'Health information technology and its impact on the quality and cost of healthcare delivery', Decision Support Systems, 55, pp. 438-449.

Bardhan, I., J. Oh, H., Z. Zheng and K. Kirksey (2015). 'Predictive analytics for readmission of patients with congestive heart failure', Information Systems Research, 26, pp. 19-39.

Barney, J. (1991). 'Firm resources and sustained competitive advantage', Journal of Management, 17, pp. 99-120.

Barreto, I. (2010). 'Dynamic capabilities: A review of past research and an agenda for the future', Journal of Management, 36, pp. 256-280.

Bergh, D. D. and E. N. K. Lim (2008). 'Learning how to restructure: Absorptive capacity and improvisational views of restructuring actions and performance', Strategic Management Journal, 29, pp. 593-61 
Bharadwaj, A. S. (2000). 'A resource-based perspective on information technology capability and firm performance: An empirical investigation', MIS Quarterly, 24, pp. 169-196.

Cao, G., Y. Duan and G. Li (2015). 'Linking business analytics to decision making effectiveness: A path model analysis', IEEE Transactions on Engineering Management, 62, 384-395.

Cegielski, C. G. and L. A. Jones-Farmer (2016). 'Knowledge, skills, and abilities for entry-level business analytics positions: A multi-method study', Decision Sciences Journal of Innovative Education, 14, pp. 91-118.

Chiang, R. H., P. Goes and E. A. Stohr (2012). 'Business intelligence and analytics education, and program development: A unique opportunity for the information systems discipline', ACM Transactions on Management Information Systems (TMIS), 3, Article 12.

Chin, W. W. (1998). The partial least squares approach to structural equation modeling. In: G. A. Marcoulides (ed.), Modern Methods for Business Research (pp. 295-336). Mahwah, NJ: Lawrence Erlbaum Associates.

Côrte-Real, N., T. Oliveira and P. Ruivo (2017). 'Assessing business value of big data analytics in European firms', Journal of Business Research, 70, pp. 379-390

Davenport, T. H. (2006). 'Competing on analytics', Harvard Business Review, 84, pp. 98-107. Davenport, T. H. and D. J. Patil (2012). 'Data scientist: The sexiest job of the $21^{\text {st }}$ century', Harvard Business Review. https://hbr.org/2012/10/data-scientist-the-sexiest-job-of-the-21stcentury.

Davenport, T. H., J. G. Harris and R. Morison (2010). Analytics at Work: Smarter Decisions, Better Results, Harvard Business Press.

Davenport, T. H., J. G. Harris. (2007). Competing on analytics: The new science of winning. Harvard Business School Press, Boston, MA. 
Demchenko, Y., P. Grosso, C. D. Laat, and P. Membrey (2013). Addressing Big Data Issues in Scientific Data Infrastructure. San Diego, CA: IEEE.

Easterby-Smith, M. and I. M. Prieto, (2008). 'Dynamic capabilities and knowledge management: an integrative role for learning?', British Journal of Management, 19, pp. 235-249.

Easterby-Smith, M., M. A. Lyles and M. A. Peteraf (2009). 'Dynamic capabilities: Current debates and future directions', British Journal of Management, 20, pp. S1-S8.

Eisenhardt, K. M. and J. A. Martin (2000). 'Dynamic capabilities: What are they?', Strategic Management Journal, 21, pp. 1105-1121.

El Sawy, O. A. and P. A. Pavlou (2008). 'IT-enabled business capabilities for turbulent environments', MIS Quarterly Executive, 7, pp. 139-150.

El Sawy, O. A., A. Malhotra, Y. Park and P. A. Pavlou (2010). 'Seeking the configurations of digital ecodynamics: It takes three to tango', Information Systems Research, 21, pp. 835-848.

Fichman, R. G. (2004). 'Going beyond the dominant paradigm for information technology innovation research: Emerging concepts and methods', Journal of the Association for Information Systems, 5, pp. 314-355.

Fink, L., N. Yogev and A. Even (2017). 'Business Intelligence and Organisational Learning: An Empirical Investigation of Value Creation Processes', Information \& Management, 54, 3856.

Fiss, P. C. (2007). 'A set-theoretic approach to organisational configurations', Academy of Management Review, 32, pp. 1180-1198.

Fiss, P. C. (2011). 'Building better causal theories: A fuzzy set approach to typologies in organisation research', Academy of Management Journal, 54, pp. 393-420. 
Fiss, P. C., B. Cambré and A. Marx (2013). Configurational Theory and Methods in Organisational Research (Vol. 38). Bingley, UK: Emerald Group Publishing.

Fornell, C. and D. F. Larcker, (1981). 'Evaluating structural equation models with unobservable variables and measurement error', Journal of Marketing Research, 18, pp. 39-50.

Galbraith, J. R. (1974). 'Organisation design: An information processing view', Interfaces, 4, pp. 28-36.

Gandomi, A., \& M. Haider (2015). Beyond the hype: Big data concepts, methods, and analytics. International Journal of Information Management, 35, pp. 137-144.

Gefen, D., D. W. Straub and M. C. Boudreau (2000). 'Structural equation modeling techniques and regression: Guidelines for research practice', Communications of the Association for Information Systems, 4, 1-78.

Ghosh, B. and J. E. Scott (2011). 'Antecedents and catalysts for developing a healthcare analytic capability', Communications of the Association for Information Systems, 29, pp. 395-409.

Goh, J. M., G. Gao and R. Agarwal (2011). 'Evolving work routines: Adaptive routinization of information technology in healthcare', Information Systems Research, 22, pp. 565-585.

Grant, R. M. (1996). 'Toward a knowledge-based theory of the firm', Strategic Management Journal, 17, pp. 109-122.

Gupta, M. and J. F. George, (2016). 'Toward the development of a big data analytics capability', Information \& Management, 53, pp. 1049-1064.

Hadida, A. L. and W. Tarvainen (2014). 'Organisational improvisation: A consolidating review and framework', International Journal of Management Reviews, 17, pp. 437-459.

Hus, B. S. and E. Griese (2018). 'Making better use of health care data', Harvard Business Review, Available at: https://hbr.org/2018/03/making-better-use-of-health-care-data. 
Jagadish, H. V., J. Gehrke, A. Labrinidis, Y. Papakonstantinou, J. M. Patel, R. Ramakrishnan and C. Shahabi (2014). 'Big data and its technical challenges', Communications of the ACM, 57, pp. 86-94.

Kallinikos, J. and N. Tempini (2014). 'Patient data as medical facts: Social media practices as a foundation for medical knowledge creation', Information Systems Research, 25, 817-833.

Kettinger, W., C. Zhang and D. A. Marchand (2011). 'CIO and business executive leadership approaches to establishing company-wide information orientation', MIS Quarterly Executive, 10, pp. 157-174.

Khatri, V. and C. V. Brown (2010). 'Designing data governance', Communications of the ACM, 53, pp. 148-152.

Kiron, D. and R. Shockley (2011). 'Creating business value with analytics', MIT Sloan Management Review, 53, pp. 57-63.

Kiron, D., P. K. Prentice and R. B. Ferguson (2012). 'Innovating with analytics', MIT Sloan Management Review, 54, pp. 47-51.

Kiron, D., R. B. Ferguson and P. K. Prentice (2013). 'From value to vision: Reimagining the possible with data analytics', MIT Sloan Management Review, 54, pp. 1-19.

Kohli, R. and V. Grover (2008). 'Business value of IT: An essay on expanding research directions to keep up with the times', Journal of the Association for Information Systems, 9, pp. 22-39.

Kooper, M. N., R. Maes and E. R. Lindgreen (2011). 'On the governance of information: Introducing a new concept of governance to support the management of information', International Journal of Information Management, 31, pp. 195-200. 
Kowalczyk, D. W. I. M. and P. Buxmann, (2014). 'Big data and information processing in organisational decision processes', Business \& Information Systems Engineering, 6, pp. 267278.

LaValle, S., E. Lesser, R. Shockley, M. S. Hopkins and N. Kruschwitz (2011). 'Big data, analytics and the path from insights to value', MIT Sloan Management Review, 52, pp. 21-31.

Lee, Y., S. Madnick, R. Wang, F. Wang and H. Zhang (2014). 'A cubic framework for the chief data officer: Succeeding in a world of big data', MIS Quarterly Executive, 13, pp. 1-13.

Legewie, N. (2013). 'An introduction to applied data analysis with qualitative comparative analysis', Forum Qualitative Sozialforschung/Forum: Qualitative Social Research, 14, article 15 .

Lindell, M. K. and D. J. Whitney (2001). 'Accounting for common method variance in crosssectional research designs', Journal of Applied Psychology, 86, pp. 114-121.

Liu, Y., J. Mezei, V. Kostakos and H. Li (2017). 'Applying configurational analysis to IS behavioural research: A methodological alternative for modelling combinatorial complexities', Information Systems Journal, 27, pp. 59-89.

Loshin, D. (2010). Master Data Management. Burlington, MA: Morgan Kaufmann.

Luo, J., M. Fan and H. Zhang (2012). 'Information technology and organisational capabilities: A longitudinal study of the apparel industry', Decision Support Systems, 53, pp. 186-194.

Mamonov, S., R. Misra and R. Jain (2015). 'Business Analytics in Practice and in Education: A Competency based Perspective', Information Systems Education Journal, 13, pp. 4-13.

McAfee, A. and E. Brynjolfsson (2012). 'Big data: The management revolution', Harvard Business Review, 90, pp. 59-68. 
Melville, N., K. Kraemer and V. Gurbaxani (2004). 'Review - Information technology and organisational performance: An integrative model of IT business value', MIS Quarterly, 28, pp. 283-322.

Mikalef, P. and A. Pateli (2017). 'Information technology-enabled dynamic capabilities and their indirect effect on competitive performance: Findings from PLS-SEM and fsQCA', Journal of Business Research, 70, pp. 1-16.

Misangyi, V. F., T. Greckhamer, S. Furnari, P. C. Fiss, D. Crilly and R. Aguilera (2017). 'Embracing causal complexity: The emergence of a neo-configurational perspective', Journal of Management, 43(1), pp. 255-282.

Moorman, C. and A. S. Miner (1998). 'Organisational improvisation and organisational memory', Academy of Management Review, 23, pp. 698-723.

Nevo, S. and M. R. Wade, (2010). 'The formation and value of IT-enabled resources: Antecedents and consequences of synergistic relationships', MIS Quarterly, 34, pp. 163-183.

Novak, L., J. Brooks, C. Gadd, S. Anders and N. Lorenzi (2012). 'Mediating the intersections of organisational routines during the introduction of a health IT system', European Journal of Information Systems, 21, pp. 552-569.

Park, Y. and O. A. El Sawy (2013). 'The value of configurational approaches for studying digital business strategy', Research in the Sociology of Organisations, 38, pp. 205-224.

Pavlou, P. A. and O. A. El Sawy (2006). 'From IT leveraging competence to competitive advantage in turbulent environments: The case of new product development', Information Systems Research, 17, pp. 198-227. 
Pavlou, P. A., and O. A. El Sawy (2010). "The "third hand": IT-enabled competitive advantage in turbulence through improvisational capabilities', Information Systems Research, 21, pp. 443471.

Pavlou, P. A., H. Liang and Y. Xue (2007). 'Understanding and mitigating uncertainty in online environments: A principal-agent perspective', MIS Quarterly, 31, pp. 105-136.

Podsakoff, P. M. and D. W. Organ (1986). 'Self-reports in organisational research: Problems and prospects', Journal of Management, 12, pp. 531-544.

Podsakoff, P. M., S. B. MacKenzie, J. Y. Lee and N. P. Podsakoff(2003). 'Common method biases in behavioral research: A critical review of the literature and recommended remedies', Journal of Applied Psychology, 88, pp. 879-903.

Popovič, A., R. Hackney, P. S. Coelho and J. Jaklič (2012). 'Towards business intelligence systems success: Effects of maturity and culture on analytical decision making', Decision Support Systems, 54, pp. 729-739.

Popovič, A., R. Hackney, R. Tassabehji and M. Castelli (2018). 'The impact of big data analytics on firms' high value business performance', Information Systems Frontiers, 20(2), pp. 209222.

Raghupathi, W. and V. Raghupathi (2014). 'Big data analytics in healthcare: Promise and potential', Health Information Science and Systems, 2, pp. 1-10.

Ragin, C. C. (1987). The Comparative Method: Moving Beyond Qualitative and Quantitative Strategies. Berkeley: University of California Press.

Ragin, C. C. (2000). Fuzzy-Set Social Science. Chicago: University of Chicago Press.

Ragin, C. C. (2008a). Redesigning Social Inquiry: Fuzzy Sets and Beyond. Chicago: University of Chicago Press. 
Ragin, C. C. (2008b). User's Guide to Fuzzy-Set/Qualitative Comparative Analysis 2.0. Tucson, AZ: Department of Sociology, University of Arizona.

Ragin, C. C. and P. C. Fiss (2008). Net effects analysis versus configurational analysis: An empirical demonstration. In C. C. Ragin (ed.), Redesigning Social Inquiry: Fuzzy Sets and Beyond (pp. 190-212). Chicago: University of Chicago Press.

Ragin, C. C., K. A. Drass, and S. Davey (2006.) Fuzzy-Set/Qualitative Comparative Analysis 2.0. Tucson, AZ: Department of Sociology, University of Arizona.

Rai, A., R. Patnayakuni and N. Seth (2006). 'Firm performance impacts of digitally enabled supply chain integration capabilities', MIS Quarterly, 30, pp. 225-246.

Ravasi, D. and M. Schultz (2006). 'Responding to organisational identity threats: Exploring the role of organisational culture', Academy of Management Journal, 49, pp. 433-458.

Rihoux, B. and C. C. Ragin (2009). Configurational Comparative Methods: Qualitative Comparative Analysis (QCA) and Related Techniques, Thousand Oaks, CA: SAGE.

Roberts, N. and V. Grover (2012). 'Leveraging information technology infrastructure to facilitate a firm's customer agility and competitive activity: An empirical investigation', Journal of Management Information Systems, 28, pp. 231-270.

Roski, J., G. Bo-Linn and T. Andrews (2014). 'Creating value in health care through big data: opportunities and policy implications', Health Affairs, 33, pp. 1115-1122.

Ross, J. W., C. M. Beath and A. Quaadgras (2013). 'You may not need big data after all', Harvard Business Review, 91, pp. 90-98.

Samorani, M. and L. R. LaGanga (2015). 'Outpatient appointment scheduling given individual day-dependent no-show predictions', European Journal of Operational Research, 240, pp. 245-257. 
Schryen, G. (2013). 'Revisiting IS business value research: What we already know, what we still need to know, and how we can get there', European Journal of Information Systems, 22, pp. 139-169.

Seddon, P. B., D. Constantinidis and H. Dod (2012). 'How does business analytics contribute to business value?' Proceeding of the 33rd International Conference on Information Systems, Orlando, Florida, USA.

Shah, N. D. and J. Pathak (2014). Why health care may finally be ready for Big Data. Retrieved January 12, 2015 from Harvard Business Review: https://hbr.org/2014/12/why-health-caremay-finally-be-ready-for-big-data.

Sharma, R., S. Mithas and A. Kankanhalli (2014). 'Transforming decision-making processes: a research agenda for understanding the impact of business analytics on organisations', European Journal of Information Systems, 23, pp. 433-441.

Spruit, M., R. Vroon and R. Batenburg (2014). 'Towards healthcare business intelligence in longterm care: An explorative case study in the Netherlands', Computers in Human Behavior, 30, pp. 698-707.

Srinivasan, R. and M. Swink (in press). 'An investigation of visibility and flexibility as complements to supply chain analytics: An organisational information processing theory perspective', Production and Operations Management, https://doi.org/10.1111/poms.12746.

Tanriverdi, H. (2006). 'Performance effects of information technology synergies in multibusiness firms', MIS Quarterly, 30, pp. 57-77.

Teece, D. (2007). 'Explicating dynamic capabilities: The nature and microfoundations of (sustainable) enterprise performance', Strategic Management Journal, 28, pp. 1319-1350. 
Teece, D., G. Pisano and A. Shuen (1997). 'Dynamic capabilities and strategic management', Strategic Management Journal, 18, pp. 509-533.

Thiem, A. (2010). 'Set-relational fit and the formulation of transformational rules in fsQCA', COMPASSS Working Paper Series, 61, http://www.compasss.org/wpseries/Thiem2010.pdf

Treadwell, W. A. (1995). 'Fuzzy set theory movement in the social sciences', Public Administration Review, 55, pp. 91-98.

Trkman, P., K. McCormack, M. P. V. De Oliveira and M. B. Ladeira (2010). 'The impact of business analytics on supply chain performance', Decision Support Systems, 49, pp. 318-327.

Wamba, S. F., A. Gunasekaran, S. Akter, S. J. F. Ren, R. Dubey and S. J. Childe (2017). 'Big data analytics and firm performance: Effects of dynamic capabilities', Journal of Business Research, 70, pp. 356-365.

Wang, Y. and N. Hajli (2017). 'Exploring the path to big data analytics success in healthcare', Journal of Business Research, 70, pp. 287-299.

Wang, Y. and T. A. Byrd (2017). 'Business analytics-enabled decision making effectiveness through knowledge absorptive capacity in health care', Journal of Knowledge Management, 21, pp. 517-539

Wang, Y., L. Kung, and T. A. Byrd (2018a). 'Big data analytics: Understanding its capabilities and potential benefits for healthcare organisations', Technological Forecasting and Social Change. 126, pp. 3-13

Wang, Y., L. Kung, W. Y. C. Wang and C. G. Cegielski (2018b). 'An integrated big data analyticsenabled transformation model: Application to health care', Information \& Management, 55(1), pp. 64-79. 
Ward, M. J., K. A. Marsolo and C. M. Froehle (2014). 'Applications of business analytics in healthcare', Business Horizons, 57, pp. 571-582.

Watson, H. J. (2014). 'Tutorial: Big data analytics: Concepts, technologies, and applications', Communications of the Association for Information Systems, 34, pp. 1247-1268.

Wilder, C. R. and C. O. Ozgur (2015). 'Business analytics curriculum for undergraduate majors', INFORMS Transactions on Education, 15, pp. 180-187.

Winter, R., R. Gilbert and J. R. Davis (2013). Big Data: What Does It Really Cost? Cambridge, MA: Winter Corporation.

Wixom, B., B. Yen and M. Relich (2013). 'Maximizing value from business analytics', MIS Quarterly Executive 12, pp. 111-123.

Wixom, B., T. Ariyachandra, D. E. Douglas, M. Goul, B. Gupta, L. S. Iyer, ... and O. Turetken, (2014). 'The current state of business intelligence in academia: The arrival of big data', Communications of the Association for Information Systems, 34, Article 1.

Wu, I. L. and Y. P. Hu (2012). 'Examining knowledge management enabled performance for hospital professionals: A dynamic capability view and the mediating role of process capability', Journal of the Association for Information Systems, 13, pp. 976-999.

Xu, Z., G. L. Frankwick and E. Ramirez (2016). 'Effects of Big Data analytics and traditional marketing analytics on new product success: A knowledge fusion perspective', Journal of Business Research, 69, pp. 1562-1566.

Zammuto, R. F., T. L. Griffith, A. Majchrzak, D. J. Dougherty and S. Faraj (2007). 'Information technology and the changing fabric of organisation', Organisation Science, 18(5), pp. 749762. 


\section{Appendix A. Skill Sets for Analytical Personnel}

\begin{tabular}{|c|c|c|}
\hline Studies & $\begin{array}{c}\text { Analytical personnel's technical } \\
\text { skills }\end{array}$ & $\begin{array}{c}\text { Analytical personnel's business } \\
\text { skills }\end{array}$ \\
\hline $\begin{array}{l}\text { Chiang et al. } \\
(2012)\end{array}$ & $\begin{array}{l}\text { Analytical skills (e.g. data } \\
\text { mining, deviational analysis } \\
\text { and anomaly detection, } \\
\text { geospatial and temporal } \\
\text { analysis) } \\
\text { IT skills (e.g. relational } \\
\text { databases, data warehouse, } \\
\text { Hadoop, MapReduce, } \\
\text { unstructured data management) }\end{array}$ & $\begin{array}{l}\text { - Business knowledge and } \\
\text { communication skills }\end{array}$ \\
\hline $\begin{array}{l}\text { Wixom et al. } \\
(2014)\end{array}$ & $\begin{array}{l}\text { - SQL and Query skills } \\
\text { - Basic analytics } \\
\text { - Data management } \\
\text { - Data integration } \\
\text { - Reporting (OLAP) skills } \\
\text { - Research methods } \\
\text { - Visualization } \\
\text { - Advanced analytics } \\
\text { - Data and text mining } \\
\text { - Programming } \\
\text { - No SQL skills }\end{array}$ & $\begin{array}{l}\text { - Communication skills } \\
\text { - Business requirement } \\
\text { - Business knowledge } \\
\text { - Emerging topics }\end{array}$ \\
\hline $\begin{array}{l}\text { Mamonov et al. } \\
(2014)\end{array}$ & $\begin{array}{l}\text { - Applied statistics } \\
\text { - Technical skills } \\
\text { - Analytical software }\end{array}$ & $\begin{array}{l}\text { Soft skills } \\
\text { (e.g. communication and } \\
\text { presentation, teamwork) }\end{array}$ \\
\hline $\begin{array}{l}\text { Wilder \& Ozgur } \\
(2015)\end{array}$ & $\begin{array}{l}\text { - Solid foundation in computer } \\
\text { science and mathematics } \\
\text { - Understand how data is } \\
\text { managed }\end{array}$ & $\begin{array}{l}\text { Identify and exploit business } \\
\text { opportunities, frame business } \\
\text { problems and interpret the results }\end{array}$ \\
\hline $\begin{array}{l}\text { Cegielski \& Jones- } \\
\text { Farmer (2016) }\end{array}$ & $\begin{array}{l}\text { Technical skills (e.g. ability to } \\
\text { integrate analyses from multiple } \\
\text { sources into a business solution, } \\
\text { ability to use data } \\
\text { visualization/graphical tools to } \\
\text { interpret data, and ability to frame } \\
\text { a business problem or question } \\
\text { analytically) }\end{array}$ & $\begin{array}{l}\text { Business skills } \\
\text { (e.g., independent learner, } \\
\text { organisational skills, } \\
\text { industry-specific knowledge) }\end{array}$ \\
\hline
\end{tabular}




\section{Appendix B. The definitions of key constructs used in the current study}

\begin{tabular}{|c|c|}
\hline Constructs & Definitions \\
\hline BDA capability & $\begin{array}{l}\text { The ability to acquire, store, process and analyse large amounts of } \\
\text { health data in various forms, and deliver meaningful information to } \\
\text { users, which allows them to discover business values and insights in a } \\
\text { timely fashion (Wang \& Hajli, 2017). }\end{array}$ \\
\hline $\begin{array}{l}\text { Data integration } \\
\text { capability }\end{array}$ & $\begin{array}{l}\text { The ability to transform different types of data into a data format that } \\
\text { can be read by the data analysis platform (Wang \& Byrd, 2017). }\end{array}$ \\
\hline Analytical capability & $\begin{array}{l}\text { The ability to drive decisions and actions through the extensive use of } \\
\text { data and different analytical techniques based on the specific } \\
\text { mechanisms used for analytics, thus addressing the various needs of } \\
\text { users and other stakeholders (Ghosh and Scott, 2011). }\end{array}$ \\
\hline Predictive capability & $\begin{array}{l}\text { The process of using a set of sophisticated tools to develop models and } \\
\text { estimations of what the environment will do in the future (Wessler, } \\
\text { 2013, p. 21). }\end{array}$ \\
\hline $\begin{array}{l}\text { Data interpretation } \\
\text { capability }\end{array}$ & $\begin{array}{l}\text { The ability to produce a healthcare matrix and reports that evaluate } \\
\text { patient care and service and identify areas for improvement (defined by } \\
\text { current study). }\end{array}$ \\
\hline Analytical personnel & $\begin{array}{l}\text { The members of an organisation who have an analytical mindset and } \\
\text { help derive value from BDA. }\end{array}$ \\
\hline $\begin{array}{l}\text { BDA-enabled } \\
\text { complementary } \\
\text { organisational resources }\end{array}$ & $\begin{array}{l}\text { A specific type of organisational resource with the aid of BDA that tend } \\
\text { to be tacit, idiosyncratic and deeply embedded in the organisation. }\end{array}$ \\
\hline $\begin{array}{l}\text { Evidence-based } \\
\text { decision-making culture }\end{array}$ & $\begin{array}{l}\text { An organisational culture of embracing evidence-based management } \\
\text { and embedding evidence-based decision-making in the core values and } \\
\text { processes of the organisation (Davenport et al., 2010). }\end{array}$ \\
\hline Data governance & $\begin{array}{l}\text { Built on IT governance, aims to formulate data rules and policies and } \\
\text { provide a vision and guidelines relating to privacy, security, lifecycle } \\
\text { and ownership of data by aligning the objectives of multiple functions } \\
\text { (Kooper, Maes, and Lindgreen, 2011; LaValle et al., 2011). }\end{array}$ \\
\hline $\begin{array}{l}\text { Organisational } \\
\text { capability }\end{array}$ & $\begin{array}{l}\text { The ability to adapt to ongoing changes in the business processes and } \\
\text { functional activities of the firm (Luo et al., 2012). }\end{array}$ \\
\hline Dynamic capability & $\begin{array}{l}\text { The ability to sense and shape opportunities and threats, seize market } \\
\text { opportunities and maintain competitiveness (Barreto, 2010; Teece, } \\
\text { 2007). }\end{array}$ \\
\hline $\begin{array}{l}\text { Improvisational } \\
\text { capability }\end{array}$ & $\begin{array}{l}\text { An organisation's learned ability to respond to unexpected } \\
\text { environmental turbulence quickly, simultaneously forming and } \\
\text { executing novel solutions by reconfiguring available resources (Pavlou } \\
\text { and El Sawy, 2010). }\end{array}$ \\
\hline
\end{tabular}




\section{Appendix C. Measurement and Items}

\begin{tabular}{|c|c|}
\hline \multicolumn{2}{|l|}{ BDA capabilities } \\
\hline $\begin{array}{l}\text { Data integration } \\
\text { capability (Wang and } \\
\text { Byrd, 2017) }\end{array}$ & $\begin{array}{l}\text { - Integrate seamlessly clinical data across multiple } \\
\text { departments in real-time or near real-time } \\
\text { - Track medical events based on the rules that have been built } \\
\text { on hospital claims } \\
\text { - Search clinical databases for all data related to patients }\end{array}$ \\
\hline $\begin{array}{l}\text { Analytical capability } \\
\text { (Wang and Byrd, 2017) }\end{array}$ & $\begin{array}{l}\text { - Analyse large amounts of clinical data to understand the past } \\
\text { and current state for specific target variables } \\
\text { - Explore the causes of medical events from clinical data } \\
\text { - Support real-time processing of multiple clinical data streams }\end{array}$ \\
\hline $\begin{array}{l}\text { Predictive capability } \\
\text { (Wang } \text { et al., 2017) }\end{array}$ & $\begin{array}{l}\text { - } \begin{array}{l}\text { Discover patterns among specific variables of interest across } \\
\text { departments }\end{array} \\
\text { - Analyse data from different sources and use the results to } \\
\text { predict future trends } \\
\text { - Provide actionable insights from clinical data in a format } \\
\text { readily understood by healthcare providers }\end{array}$ \\
\hline $\begin{array}{l}\text { Data interpretation } \\
\text { capability (Wang and } \\
\text { Byrd, 2017) }\end{array}$ & $\begin{array}{l}\text { - Generate clinical summary in real-time or near real-time and } \\
\text { present in visual dashboards } \\
\text { - Provide outputs for role-based decision-making }\end{array}$ \\
\hline \multicolumn{2}{|c|}{ Analytics personnel skills } \\
\hline $\begin{array}{l}\text { Technical skills } \\
\text { (Cegielski and Jones- } \\
\text { Farmer, 2016) }\end{array}$ & $\begin{array}{l}\text { - Ability to integrate analyses from multiple sources into a } \\
\text { business solution } \\
\text { - Ability to use data visualization/graphical tools to interpret } \\
\text { data } \\
\text { - Ability to frame a business problem or question analytically } \\
\text { - Ability to solve pre-framed business problems or questions } \\
\text { analytically }\end{array}$ \\
\hline $\begin{array}{l}\text { Business skills (Cegielski } \\
\text { and Jones-Farmer, 2016) }\end{array}$ & $\begin{array}{l}\text { - Ability to be an independent learner } \\
\text { - Organisational skills } \\
\text { - Healthcare knowledge }\end{array}$ \\
\hline \multicolumn{2}{|c|}{ Complementary organisational resources } \\
\hline $\begin{array}{l}\text { Evidence-based decision- } \\
\text { making culture (Popovič } \\
\text { et al., 2012) }\end{array}$ & $\begin{array}{l}\text { - Our hospital usually uses evidence-based insights for the } \\
\text { creation of new healthcare service } \\
\text { - Our hospital is open to new ideas and approaches that } \\
\text { challenge current or future projects on the basis of new } \\
\text { insights } \\
\text { - Our hospital allows the incorporation of available information } \\
\text { within any decision-making process. }\end{array}$ \\
\hline $\begin{array}{l}\text { Data governance (Khatri } \\
\text { and Brown, 2010) }\end{array}$ & $\begin{array}{l}\text { - Data principle (clarifying the role of data as an asset) } \\
\text { - Data quality (establishing the requirements of intended use of } \\
\text { data) } \\
\text { - Metadata (establishing the semantics of data so that it is } \\
\text { interpretable by the users) }\end{array}$ \\
\hline
\end{tabular}




\begin{tabular}{|c|c|}
\hline & $\begin{array}{l}\text { - Data access (specifying access requirements of data) } \\
\text { - Data lifecycle (determining the definition, production, } \\
\text { retention and retirement of data) }\end{array}$ \\
\hline \multicolumn{2}{|c|}{ Organisational capabilities } \\
\hline $\begin{array}{l}\text { Planned dynamic } \\
\text { capabilities (Pavlou and } \\
\text { El Sawy, 2010) }\end{array}$ & $\begin{array}{l}\text { - Our hospital frequently generates, disseminate, and respond } \\
\text { to market intelligence about customer needs } \\
\text { - Our hospital has adequate routines to acquire, assimilate, } \\
\text { transform, and exploit existing resources to generate new } \\
\text { knowledge } \\
\text { - Our hospital is effective in managing dependencies among } \\
\text { resources and tasks to synchronize activities } \\
\text { - Our hospital effectively integrates disparate employees, } \\
\text { inputs through heedful contribution, representation, and } \\
\text { interrelation into our group }\end{array}$ \\
\hline $\begin{array}{l}\text { Improvisational } \\
\text { capabilities (Pavlou and } \\
\text { El Sawy, 2010) }\end{array}$ & $\begin{array}{l}\text { - Our hospital is successful in figuring out our actions as we go } \\
\text { along } \\
\text { - Our hospital effectively improvises when carrying out our } \\
\text { activities } \\
\text { - Our hospital could spontaneously readjust our activities } \\
\text { according to competitive environments }\end{array}$ \\
\hline
\end{tabular}

\section{Measurement for quality of care}

As Agarwal et al.'s (2010) health information technology impact framework suggests, we operationalize healthcare performance by using quality of care. Quality of care is a key component of the business value expected from healthcare information technologies (Bardhan and Thouin, 2013). To assess the quality of care, we took advantage of the recently released Hospital Compare Data database to gather data from the Hospital Readmissions Reduction Program (HRRP) and the Hospital Value-Based Purchasing (HVBP) Program. A hospital's excess readmission ratio is a measure of that hospital's readmission performance compared to the national average for a comparable set of patients with the same conditions. While there are a variety of quality outcome measures that could be considered, we chose excess readmission ratio, as this most accurately reflects the total process of care received. Hospitals can provide a better quality of care if the risk of being readmitted for the same diagnosis in the future is reduced (Bardhan, Oh, Zheng and 
Kirksey, 2015). The average excess readmission ratio (AERR) was calculated using the following formulae; the higher the ratio the worse the quality of care.

(1) Excess readmission ratio $=$ risk-adjusted predicted readmissions/risk-adjusted expected readmissions.

(2) Average excess readmission ratio $=($ Excess Readmission Ratio for Pneumonia + Excess Readmission Ratio for heart failure + Excess Readmission Ratio for acute myocardial infarction + Excess Readmission Ratio for total hip/knee arthroplasty + Excess Readmission Ratio for Chronic Obstructive Pulmonary Disease)/5

Another way to measure the quality of care is in terms of the patient satisfaction data provided by the Hospital Value-Based Purchasing (HVBP) programme from CMS. This programme is part of CMS' long-standing effort to link Medicare's payment system to quality. The programme implements value-based purchasing for the payment system that accounts for the largest share of Medicare spending. Hospitals are paid for inpatient acute care services based on the quality of care, not just the quantity of the services they provide. From this data, two domains can be used to assess hospital performance: (1) Patient experience of care and (2) Clinical process of care. The patient experience of care domain is comprised of the Hospital Consumer Assessment of Healthcare Providers and Systems (HCAHPS) Survey measures. The Clinical Process of Care domain is comprised of selected Inpatient Quality Reporting (IQR) Programme's Process of Care measures from the Acute Myocardial Infarction (AMI), Healthcare Associated Infections (HAI), Heart Failure (HF), Pneumonia (PN), and Surgical Care Improvement Project (SCIP) measure sets. A performance score and an improvement score are calculated for each measure, after which a domain score is calculated for each of the two domains. The Total Performance Score (TPS) is calculated using the weighted domain scores. The Clinical Process of Care domain score is 
weighted as $70 \%$ of the TPS, and the Patient Experience of Care domain is weighted as $30 \%$ of the TPS. 


\section{Appendix D. Item Loadings and Cross Loadings}

\begin{tabular}{|c|c|c|c|c|c|c|c|c|c|c|}
\hline & DIA & ANA & INT & PRE & $\mathrm{TS}$ & BS & CUL & DG & DYN & IM \\
\hline DIA1 & .801 & -.096 & .091 & .020 & .167 & -.118 & .057 & .033 & .273 & .027 \\
\hline DIA2 & .782 & .180 & .173 & -.088 & .268 & .072 & .089 & -.070 & .193 & -.104 \\
\hline DIA3 & .886 & .028 & -.010 & .097 & .124 & .060 & .086 & -.064 & .036 & $\begin{array}{l}-.009 \\
\end{array}$ \\
\hline ANA1 & .077 & .873 & .103 & .094 & -.004 & -.047 & .101 & -.078 & -.046 & .258 \\
\hline ANA2 & .021 & .913 & -.024 & .118 & -.089 & .080 & .032 & -.107 & -.038 & .121 \\
\hline ANA3 & -.023 & .802 & .135 & .094 & -.245 & -.053 & .034 & -.025 & .105 & .202 \\
\hline INT1 & .045 & .092 & .907 & .074 & -.113 & .069 & .047 & -.152 & .164 & -.004 \\
\hline INT2 & .181 & .085 & .843 & .168 & -.205 & .100 & .073 & -.129 & -.041 & .170 \\
\hline PRE1 & .098 & .072 & .150 & .867 & .099 & .090 & .093 & -.090 & -.005 & .067 \\
\hline PRE2 & -.020 & .184 & -.004 & .832 & .269 & -.019 & -.009 & .034 & .014 & .059 \\
\hline PRE3 & -.017 & .048 & .073 & .836 & .144 & .196 & -.072 & -.048 & .005 & .053 \\
\hline TS1 & .065 & -.082 & -.123 & .192 & .833 & .094 & -.057 & -.010 & .179 & .075 \\
\hline TS2 & .127 & -.100 & -.035 & .060 & .865 & .089 & -.037 & .090 & .162 & -.008 \\
\hline TS3 & .188 & -.131 & -.132 & .201 & .792 & .262 & -.016 & -.026 & .112 & -.016 \\
\hline TS4 & .208 & -.054 & -.051 & .149 & .804 & -.011 & -.061 & .081 & .091 & -.229 \\
\hline BS1 & .013 & .101 & .266 & .060 & .156 & .731 & .271 & .058 & -.142 & -.018 \\
\hline BS2 & .015 & -.102 & -.042 & -.008 & .133 & .853 & -.069 & -.016 & .027 & .056 \\
\hline BS3 & -.015 & .031 & .032 & .246 & .063 & .828 & .069 & .155 & -.060 & .022 \\
\hline CUL1 & .128 & -.006 & -.015 & -.151 & -.074 & -.040 & .922 & .003 & -.063 & .030 \\
\hline CUL2 & .054 & .154 & .084 & .057 & -.045 & .122 & .833 & -.156 & -.096 & .077 \\
\hline CUL3 & .038 & .014 & .060 & .130 & -.029 & .111 & .778 & -.292 & -.124 & .206 \\
\hline DG1 & -.157 & -.256 & -.115 & -.028 & .172 & .040 & -.012 & .812 & .087 & .052 \\
\hline DG2 & .031 & -.267 & -.281 & -.026 & .056 & .030 & .002 & .765 & -.003 & -.069 \\
\hline DG3 & -.062 & .039 & -.014 & .077 & -.039 & .037 & -.206 & .804 & .044 & .059 \\
\hline DG4 & .034 & .069 & .028 & -.124 & .086 & .110 & -.014 & .650 & -.228 & .041 \\
\hline DG5 & .029 & .053 & -.009 & -.019 & -.104 & -.025 & -.155 & .806 & -.009 & -.180 \\
\hline DYN1 & .091 & -.011 & -.093 & -.054 & .161 & -.034 & -.282 & .032 & .768 & -.114 \\
\hline DYN2 & .189 & .000 & .023 & .034 & .073 & -.070 & -.041 & -.058 & .883 & .054 \\
\hline DYN3 & .128 & -.090 & .035 & .084 & .110 & -.089 & -.046 & .008 & .915 & .067 \\
\hline DYN4 & .042 & .189 & .274 & -.100 & .282 & .093 & .043 & -.118 & .715 & -.211 \\
\hline IM1 & .020 & .245 & .228 & .072 & -.067 & .024 & .174 & -.001 & -.077 & .832 \\
\hline IM2 & -.015 & .152 & -.008 & -.074 & .055 & .046 & .046 & -.079 & .045 & .898 \\
\hline IM3 & -.070 & .174 & -.039 & .217 & -.142 & .004 & .079 & .011 & -.078 & .827 \\
\hline
\end{tabular}

Note: DIA = data integration capability; ANA = analytical capability; INT = data interpretation capability; PRE = predictive capability; TS = personnel's technical skills; BS = personnel's business skills; CUL = evidence-based decision making culture; DG = data governance; DYN = planned dynamic capabilities; IM $=$ improvisational capabilities. Bold numbers indicate item loadings on the assigned constructs. 


\section{Author Biography}

Yichuan Wang is a Lecturer (Assistant Professor) in Marketing at Newcastle University. He earned his Ph.D. in Business \& Information Systems from Auburn University (USA). His research interests focus on big data analytics for healthcare and sustainable development. His work has been published in the academic journals, including Annals of Tourism Research, Journal of Business Research, Industrial Marketing Management, Information \& Management, IEEE Transactions on Engineering Management, International Journal of Production Economics, Technological Forecasting and Social Change, Computers in Human Behavior, and Journal of Knowledge Management. He is the recipient of the Newcastle University's Research Excellence Award in 2018.

LeeAnn Kung is an Assistant professor of Information Systems at Georgia Southern University. She earned her Ph.D. of Business (MIS) from Auburn University in 2015. She also earned a MS of Information Science from University at Albany, SUNY and a M.Ed. from National-Louis University. Her research interests include Organizational capabilities, Business value of Information Systems and Innovations, and Big Data. She has published in top IS and business journals such as the Journal of Information Technology, Industrial Marketing Management, Information and Management, Technological Forecasting and Social Change, and Journal of Enterprise Information Management.

Suraksha Gupta is the Professor of Socially Responsible Marketing at Newcastle University London. She holds a PhD from Brunel University in UK, MBA from Institute of Management Technology in India and Bachelor of Commerce from University of Delhi, India. Her research publications have appeared in highly reputed journals such as Journal of World Business, Journal of Business Research, Industrial Marketing Management, European Journal of Marketing, Technological Forecasting and Social Change, and Thunderbird International Business Review.

Sena Ozdemir is a Senior Lecturer in Marketing at Coventry University, Business School, United Kingdom. Her research focuses on strategic new product alliances, global product development, the use of Big Data in the customer and marketing analytics process, inter- firm cross-functional NPD team integration, and social innovation. Her publications have appeared in journals such as Industrial Marketing Management, Journal of Business Research, and Innovation: Organization \& Management, and so forth. 